\title{
QFT Based Robust Positioning Control of the PMSM Using Automatic Loop Shaping with Teaching Learning Optimization
}

\author{
Nitish Katal and Shiv Narayan \\ Electrical Engineering Department, PEC University of Technology, Chandigarh, India \\ Correspondence should be addressed to Nitish Katal; nitishkatal@gmail.com
}

Received 14 August 2016; Revised 17 November 2016; Accepted 21 November 2016

Academic Editor: Zhiping Qiu

Copyright (c) 2016 N. Katal and S. Narayan. This is an open access article distributed under the Creative Commons Attribution License, which permits unrestricted use, distribution, and reproduction in any medium, provided the original work is properly cited.

\begin{abstract}
Automation of the robust control system synthesis for uncertain systems is of great practical interest. In this paper, the loop shaping step for synthesizing quantitative feedback theory (QFT) based controller for a two-phase permanent magnet stepper motor (PMSM) has been automated using teaching learning-based optimization (TLBO) algorithm. The QFT controller design problem has been posed as an optimization problem and TLBO algorithm has been used to minimize the proposed cost function. This facilitates designing low-order fixed-structure controller, eliminates the need of manual loop shaping step on the Nichols charts, and prevents the overdesign of the controller. A performance comparison of the designed controller has been made with the classical PID tuning method of Ziegler-Nichols and QFT controller tuned using other optimization algorithms. The simulation results show that the designed QFT controller using TLBO offers robust stability, disturbance rejection, and proper reference tracking over a range of PMSM's parametric uncertainties as compared to the classical design techniques.
\end{abstract}

\section{Introduction}

Issac Horowitz introduced a frequency domain robust controller design method of quantitative feedback theory (QFT) in the 1960s. QFT uses Bode's famous gain-phase integrals for designing controllers, which are robust over a range of plant's parametric uncertainties. Nichols chart is used for synthesizing the controller such that it satisfies the prespecified performance objectives [1]. One of the key steps in synthesizing the QFT controller is the loop shaping, such that $L_{0}(j \omega)$ satisfies the QFT bounds on the nominal loop transmission at each design frequency. Automating the loop shaping step is still an open problem for designing the QFT controllers, which is performed manually and requires a lot of design experience; and still, there is no guarantee that an optimal controller is obtained [2]. In this paper, the automatic loop shaping of the QFT controllers has been performed using teaching learningbased optimization (TLBO) for the robust positioning control of a 2-phase permanent magnet stepper motor such that it offers a robust performance over a range of parametric uncertainties.
Permanent magnet stepping motor (PMSM) is an electromechanical actuator generally used in applications that require precise incremental motion, such as robotics, harddrives, and process control. Inherently, PMSM exhibits nonlinear and uncertain behavior because of continuous operation and time varying motor characteristics. With the varying dynamics of the motor, the control system fails to accurately control the motor. If these motors are not properly controlled, resonance may occur. Thus, it becomes essential for the controller that it must exert a quality control and that too in the presence of uncertainties, as it directly affects the process safety and quality of products. Thus the controller must be designed such that it shows a robust response over a range of plant's parametric uncertainties.

In this paper, the use of QFT based controller has been considered for the robust positioning control of a 2phase permanent magnet stepper motor. QFT is a frequency domain controller design technique that can efficiently minimize the effect of parametric uncertainties in the system. The design of QFT controller is not a simple process, as it requires eminent loop shaping experience and still there is 
no guarantee that an optimal controller has been obtained. In this work, the loop shaping step required for synthesizing the controller has been automated by expressing the design process as an optimization problem. By doing so, the need for generation of templates and bounds is eliminated and by minimizing the proposed cost function, an optimal controller can be obtained. This also facilitates prespecifying the controller structure, which is not possible in standard QFT design, facilitating designing low-order controllers.

In this paper, for formulating the objective function, QFT design objectives of sensitivity and robust stability have been considered. Minimization of the magnitude of the sensitivity function at each design frequency ensures good tracking performance and the minimization of complementary sensitivity ensures good noise rejection. The objective function has been expressed as aggregate-of-function and teaching learningbased optimization (TLBO) algorithm has been used to minimize it. TLBO offers advantages over established algorithms as it does not have any algorithm-specific controlling parameters and only requires parameters of population size and number of iterations. Improper selection of algorithmspecific parameters leads to increased computational effort and the solution may not be globally optimal. In order to verify the robustness of the TLBO tuned QFT controller, two cases of parametric uncertainty in PMSM have been considered with $\pm 10 \%$ and $\pm 40 \%$ variation in the nominal value. A comparison has also been made against the classical PID tuning method of Ziegler-Nichols and QFT controller designed by different optimization algorithms, like genetic algorithm (GA), simulated annealing (SA), bat algorithm (BA), and particle swarm optimization (PSO). From the results obtained in this paper, the TLBO tuned QFT controller efficiently handles the parametric uncertainties in a very tight envelope even with a low order controller.

The paper has been categorized into the following sections: Section 2 provides a review of the literature. Section 3 deals with the mathematical modeling of the permanent magnet stepper motor and also discusses the variation of the PMSM parameters causing parametric uncertainty. Section 4 deals with the quantitative feedback theory. Teaching learning-based optimization has been discussed in Section 5, followed by the automatic loop shaping procedure for the design of QFT controllers in Section 6. In Section 7 the results obtained have been discussed and the design validation in the presence of parametric uncertainties has been done in Section 8 followed by conclusions and references.

\section{Literature Review}

QFT has found colossal applications in several diverse areas ranging from missile trajectory control $[3,4]$ to electrical systems [5-7], waste treatment plants [8], aerospace applications $[9,10]$, and even some applications in civil engineering [11]. But all these techniques have been based on manual loop shaping of the open loop transmission $L_{0}(j \omega)$ on the Nichols chart and the success of the loop shaping process is solely destined upon the experience of the designer and is merely fate if an optimal controller design is achieved.
Moreover, the loop shaping becomes very challenging for uncertain and nonminimum phase systems. Even the most conscientious design does not ensure achieving the perfect optimal controller.

Still, the automatic loop shaping of QFT controllers is an open problem. Initially, some efforts have been made to automate the process; Gera and Horowitz [12] proposed a semiautomatic process, which eventually gave very high order controllers followed by Ballance and Gawthrop [13] who automated the process. Nandakumar et al. [14] designed a fixed-structure robustly stable low-order QFT controller for a nonlinear hydraulic actuator using linear programming. Comasólivas et al. [15] used global mixed-integer nonlinear programming for obtaining QFT controllers. Zolotas and Halikias [16] used the approach of obtaining the optimal QFT controllers by searching among the dense set of controllers. Yaniv [17] designed sequential QFT controller for MIMO systems using automated loop shaping. These approaches mentioned are based on the rational approximation of the controller and a low-order rational controller gives a poor response. It is impossible for the abovementioned methodologies to solve complicated multiobjective, multidimensional, and nonlinear optimization with convex or linear programming.

Patil and Nataraj [18] translated the QFT design requirements of robust stability and tracking specifications into quadratic inequalities and used interval constraint satisfaction technique (ICST) for automating the loop shaping procedure. Kalla and Nataraj [19], Patil et al. [20], and Jeyasenthil and Nataraj [21] designed QFT controller using ICST. Patil and Nataraj $[22,23]$ implemented ICST based process for designing QFT controllers for a $3 \times 3$ distillation column, nonlinear maglev system and so on. Several issues regarding the ICST approach have been reported by Goldsztejn et al. [24].

Nature inspired optimization algorithms are being increasingly addressing the problems which existing control theory cannot elucidate. Such nonlinear, nonconvex multiobjective optimization cannot be solved using conventional gradient-based optimization algorithms. The main objective is to design the QFT controller for the uncertain system, such that the cost of the feedback is minimized and all robust stability and performance specifications are met. Some researchers have pursued the use of bioinspired algorithms for designing the QFT controllers. Garcia-Sanz and Guillen [25] and Chen et al. [26] proposed genetic algorithm for loop shaping of the QFT controllers. Kim and Chung [27] used evolutionary algorithms for optimising the QFT controllers. Molins and Garcia-Sanz [28] obtained robustly stable QFT controllers using both genetic and evolutionary algorithms. Satpati et al. [29] designed robust PID based QFT controllers for first-order lag systems with minimal dead time using PSO. Meng and Xue [30] automated the loop shaping of a fractional order QFT controller using particle swarm optimization. Meng and Xue [31, 32] used particle swarm optimization for automating the loop shaping of robustly stable fractional order QFT controllers for nonminimum phase hydrosystems. But, these abovementioned techniques require the generation of templates and bounds using QFT toolbox for the loop 
shaping purpose on the Nichols chart for the design of controller.

Rao et al. [33] have introduced teaching learning-based optimization algorithm in 2011 which has been widely applied in several engineering application like power systems [34,35], mechanical systems [36-38], renewable energy systems [39], and several other diverse applications. In the design of control systems, Sahu et al. [40] used TLBO for designing a fuzzyPID based controller for automatic generation control in multiarea power systems and the robustness superiority of the TLBO based design has been compared against that of genetic algorithm (GA), particle swarm optimization (PSO), and simulated annealing (SA). Khooban [41] used TLBO for designing an intelligent PID controller for robotic application and compared its efficacy to PSO algorithm. One of the biggest advantages of TLBO is that it is an algorithmspecific parameter-less algorithm, while the other established algorithms like GA, PSO, differential evolution (DE), bat algorithm (BA), flower pollination algorithm (FPA), and so on require careful tuning of the algorithm control parameters. Improper tuning of these algorithm-specific control parameters may increase the computational effort and can yield a local optimum solution [33].

\section{Mathematical Modeling of Permanent Magnet Stepper Motor}

In this work, physical modeling approach has been used for developing the mathematical model of the considered linear motor drive as discussed in [42]. In physical modeling, system is further divided into subsystems whose behavior is known. For the PMSM, the system can be divided into two subsystems, that is, (1) electrical subsystem and (2) mechanical subsystem. These subsystems inherit nonlinearities and are exactly known and with continuous operation are subject to wear and tear; thus the dynamics of the PMSM vary with time. With this parametric uncertainty in the PMSM, the controller designed will not be able to maintain the quality of control.

3.1. Mathematical Modeling of the Mechanical Subsystem. Figure 1 shows the schematic representation of 2-phase PMSM, where each phase is denoted by $A$ and $B$ and the rotor and stator both have $2 N_{r}$ magnetic poles and uniform winding arranged at $\lambda$ intervals. The motion of the rotor has been expressed in the form of differential equations.

$$
T=J \frac{d^{2} \theta}{d t^{2}}+D \frac{d \theta}{d t}+T_{F},
$$

where $T$ is the torque generated, $J$ is the inertia of rotor, $D$ is the coefficient of viscous friction, $T_{F}$ is coulomb frictional torque, and $\theta$ is the rotor's angular position. by

Each winding produces its individual torque and is given

$$
\begin{aligned}
& T_{A}=-N_{r} n \phi_{m} i_{A} \sin \left(N_{r} \theta\right), \\
& T_{B}=-N_{r} n \phi_{m} i_{B} \sin \left(N_{r}(\theta-\lambda)\right),
\end{aligned}
$$

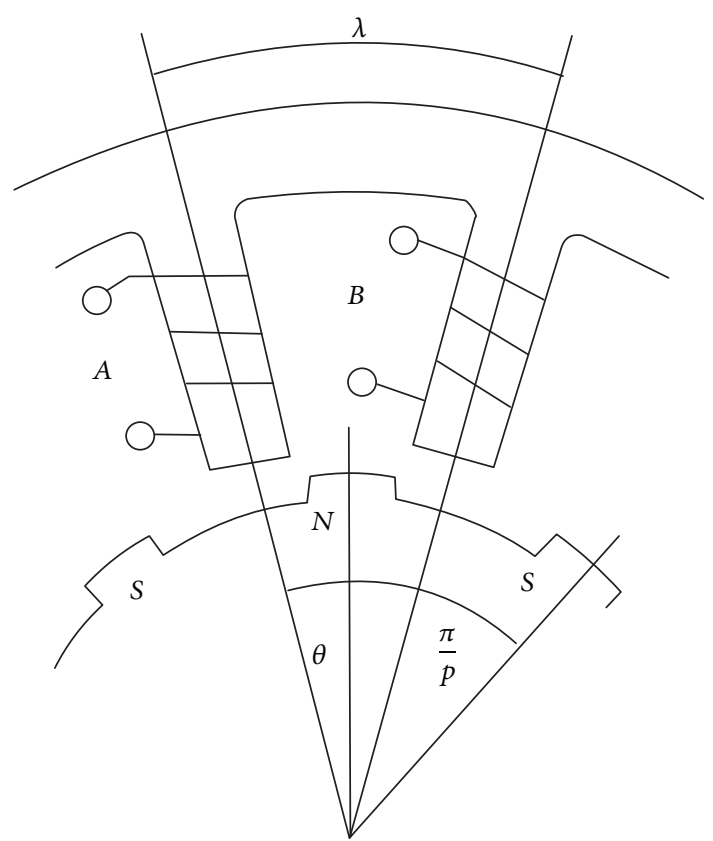

FIGURE 1: Representation of permanent 2-phase permanent magnet stepper motor.

where $T_{A}$ and $T_{B}$ is the torque produced by the current $i_{A}$ and $i_{B}$ flowing in each winding, the rotor has $N_{r}$ teeth, flux linkage is $n \phi_{m}$, and tooth pitch $\lambda$ is in radians.

Equation (3) gives the dynamic equation for the mechanical section of the PMSM and has been derived from (1)-(2) [42]:

$$
\begin{aligned}
J \frac{d^{2} \theta}{d t^{2}} & +D \frac{d \theta}{d t}+N_{r} n \phi_{m} i_{A} \sin \left(N_{r} \theta\right) \\
& +N_{r} n \phi_{m} i_{B} \sin \left(N_{r}(\theta-\lambda)\right)=0 .
\end{aligned}
$$

3.2. Mathematical Modeling of the Electrical Subsystem. The voltage equations for the stator windings can be used for modeling the electrical subsystem. For each winding, (3)-(4) can be used for expressing the whole nonlinear model of the permanent magnet stepping motor.

$$
\begin{aligned}
& V-r i_{A}-L \frac{d i_{A}}{d t}-M \frac{d i_{B}}{d t}+\frac{d}{d t}\left(n \phi_{m} \cos \left(N_{r} \theta\right)\right)=0, \\
& V-r i_{B}-L \frac{d i_{B}}{d t}-M \frac{d i_{A}}{d t}+\frac{d}{d t}\left(n \phi_{m} \cos \left(N_{r}(\theta-\lambda)\right)\right) \\
& \quad=0
\end{aligned}
$$

where $V$ is the DC terminal voltage, $L$ is the self-inductance of each phase, $M$ is the mutual inductance, and $r$ is the stator circuit resistance.

From the analytical point of view, the abovementioned equations have to be linearized. Considering that winding carries a stationary current $I_{0}$ in both phases, the equilibrium position of the stator is taken as $\theta=\lambda / 2$ as in Figure 2. The deviation from the equilibrium is denoted by $\delta \theta$, which 


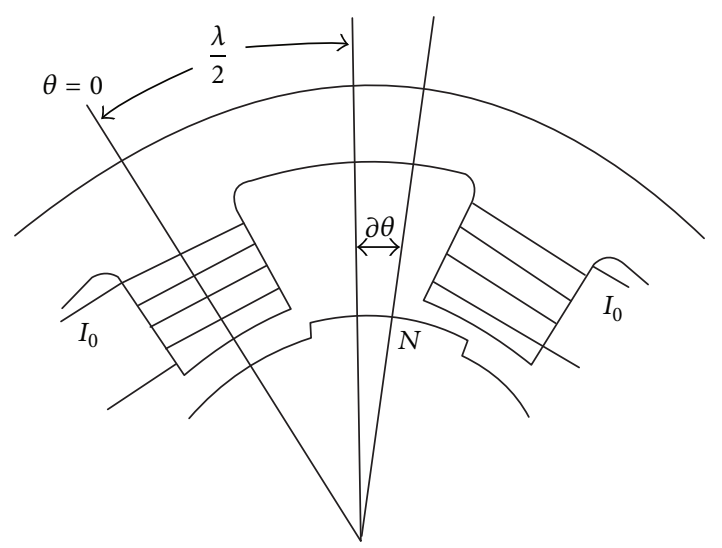

Figure 2: Two stator phases of PMSM carrying stationary current $I_{0}$.

is a function of time $t$ and is a very small entity. When the rotor revolves/oscillates, the stationary current in both the windings changes its value by $\delta i_{A}$ and $\delta i_{B}$, respectively, and the position of the rotor deviates from its equilibrium by $\delta \theta$. For the linearization of (3)-(4), the angular rotor angle $\theta$ has been chosen as

$$
\begin{gathered}
\theta=\frac{\lambda}{2}+\delta \theta, \\
i_{A}=I_{o}+\delta i_{A}, \\
i_{B}=I_{o}+\delta i_{B} .
\end{gathered}
$$

Then,

$$
\begin{aligned}
\sin \left(N_{r} \theta\right)= & \sin \left(\frac{N_{r} \lambda}{2}+N_{r} \delta \theta\right) \\
= & \sin \left(\frac{N_{r} \lambda}{2}\right) \cos \left(N_{r} \delta \theta\right) \\
& +\cos \left(\frac{N_{r} \lambda}{2}\right) \sin \left(N_{r} \delta \theta\right) .
\end{aligned}
$$

In order to take out the nonlinearities, the trigonometric functions of sin and cosine can be eliminated by considering $N_{r} \delta \theta$ to be very small.

So,

$$
\begin{aligned}
& \cos \left(N_{r} \delta \theta\right) \cong 1, \\
& \sin \left(N_{r} \delta \theta\right) \cong N_{r} \delta \theta .
\end{aligned}
$$

We simplify (6) as

$$
\sin \left(N_{r} \theta\right)=\sin \left(\frac{N_{r} \lambda}{2}\right)+N_{r} \cos \frac{N_{r} \lambda}{2}(\delta \theta)
$$

and similarly,

$$
\begin{aligned}
\sin N_{r}(\theta-\lambda) & =\sin N_{r}\left(\frac{\lambda}{2}+\delta \theta-\lambda\right) \\
& =-\sin N_{r}(\lambda-\delta \theta) \\
& =-\sin \left(\frac{N_{r} \lambda}{2}\right)+N_{r}\left(\cos \frac{N_{r} \lambda}{2}\right)(\delta \theta) .
\end{aligned}
$$

Using (5) and (8)-(9) in (3), we get

$$
\begin{gathered}
J \frac{d^{2}(\delta \theta)}{d t^{2}}+D \frac{d(\delta \theta)}{d t}+N_{r} n \phi_{m}\left(I_{0}+\delta i_{A}\right) \\
\cdot\left\{\sin \left(\frac{N_{r} \lambda}{2}\right)+N_{r} \cos \frac{N_{r} \lambda}{2}(\delta \theta)\right\} \\
-N_{r} n \phi_{m}\left(I_{0}+\delta i_{B}\right) \\
\cdot\left\{\sin \left(\frac{N_{r} \lambda}{2}\right)+N_{r}\left(\cos \frac{N_{r} \lambda}{2}\right)(\delta \theta)\right\}=0 .
\end{gathered}
$$

Ignoring the product of disturbances like $\delta i_{A} \delta \theta$ in (10), the linearized differential equation is obtained as

$$
\begin{gathered}
J \frac{d^{2}(\delta \theta)}{d t^{2}}+D \frac{d(\delta \theta)}{d t}+2 N_{r}^{2} n \phi_{m} I_{o} \cos \left(\frac{N_{r} \lambda}{2}\right) \delta \theta \\
+N_{r} n \phi_{m} \sin \left(\frac{N_{r} \lambda}{2}\right)\left(\delta i_{A}-\delta i_{B}\right)=0 .
\end{gathered}
$$

Similarly, (4) can be linearized as

$$
\begin{aligned}
& r\left(\delta i_{A}\right)+L \frac{d\left(\delta i_{A}\right)}{d t}+M \frac{d\left(\delta i_{B}\right)}{d t} \\
& -\left(N_{r} n \phi_{m} \sin \left(\frac{N_{r} \lambda}{2}\right)\right) \frac{d(\delta \theta)}{d t}=0, \\
& r\left(\delta i_{B}\right)+L \frac{d\left(\delta i_{B}\right)}{d t}+M \frac{d\left(\delta i_{A}\right)}{d t} \\
& +\left(N_{r} n \phi_{m} \sin \left(\frac{N_{r} \lambda}{2}\right)\right) \frac{d(\delta \theta)}{d t}=0 .
\end{aligned}
$$

Taking the Laplace transformation of (11)-(12) the transfer function for the two-phase PMSM can be taken as [42]

$$
G(s)=\frac{\Theta_{o}}{\Theta_{i}}=\frac{(r / L) w_{\mathrm{np}}^{2}}{s^{3}+\left(r / L_{p}+D / J\right) s^{2}+\left(r D / L_{p} J+w_{\mathrm{np}}^{2}\left(1+k_{p}\right)\right) s+\left(r / L_{p}\right) w_{\mathrm{np}}^{2}},
$$


TABLE 1: PMSM parameters with nominal values and their range.

\begin{tabular}{lccc}
\hline Parameter & Nominal value & $\pm 10 \%$ uncertainty & $\pm 40 \%$ uncertainty \\
\hline Stator resistance $(r)$, ohm & 33 & {$[29.7,36.3]$} & {$[19.8,46.2]$} \\
Self-inductance $(L), \mathrm{mH}$ & 5.4 & {$[4.86,5.94]$} & {$[3.24,7.56]$} \\
Mutual inductance $(M), \mathrm{mH}$ & 0.4 & {$[0.36,0.44]$} & - \\
Rotor inertia $(J), \mathrm{g} \cdot \mathrm{cm}^{2}$ & 0.16 & - & - \\
Number of rotor teeth $\left(N_{r}\right)$ & 6 & {$[1.215,1.485]$} & - \\
Viscous friction $(D)(\mathrm{N} \cdot \mathrm{m} \cdot \mathrm{s} / \mathrm{rad}) * 10^{-5}$ & 1.35 & - & - \\
Tooth pitch $(\lambda), \mathrm{rad}$ & $\pi / 12$ & - & - \\
Stationary current $\left(I_{o}\right), \mathrm{Amp}$ & 0.15 & {$[1.08,1.32]$} & - \\
Flux linkage $\left(n \phi_{m} T m^{2}\right) * 10^{-3}$ & 1.2 & & {$[0.72,1.68]$} \\
\hline
\end{tabular}

where $\Theta_{o}$ is the actual rotor output and $\Theta_{i}$ is the demanded (input) rotor output.

$$
\begin{aligned}
L_{p} & =L-M, \\
w_{\mathrm{np}}^{2} & =\frac{2 N_{r}^{2} n \phi_{m} I_{o} \cos \left(N_{r} \lambda / 2\right)}{J}, \\
k_{p} & =\frac{n \phi_{m} \sin ^{2}\left(N_{r} \lambda / 2\right)}{L_{p} I_{o} \cos \left(N_{r} \lambda / 2\right)} .
\end{aligned}
$$

The parametric uncertainty exhibited by PMSM has been depicted by the varying range of parameters as shown in Table 1 along with their nominal values [43]. The nominal transfer function $G_{0}(s)$ has been shown in (15). A parametric variation of $\pm 10 \%$ and $\pm 40 \%$ against the nominal values has been considered for obtaining a parametrically uncertain plant.

$$
G_{0}(s)=\frac{350}{s^{3}+15.04 \cdot s^{2}+177.8 \cdot s+378}
$$

\section{QFT}

Nowadays, in control system engineering significant emphasis is being placed on performance robustness such that the control system should be able to handle the uncertainties' which can be due to the modeling ignorance, parameter variations, nonlinearity, and so on [44]. Ample research has been carried out to address this issue and led to the foundation of several strong theories such as $H_{2}, H_{\infty}, \mathrm{LQR}$, and $\mu$-synthesis [45]. Bode in the 1940s found that the behavior shown by real systems is different from the model which has been considered in the controller design process. But still, most of the theories ignore the fact that the system considered while designing the controller is just an approximation of the actual system and the present design techniques can only deal with the fixed linear systems [44].

In the 1960s Issac Horowitz extended Bode's famous gainphase integrals and introduced quantitative feedback theory (QFT), a frequency domain controller design technique. QFT is based on the concept that only feedback is required for making a system robust and it must be shaped such that a set of objectives of tracking, disturbance rejection, robust

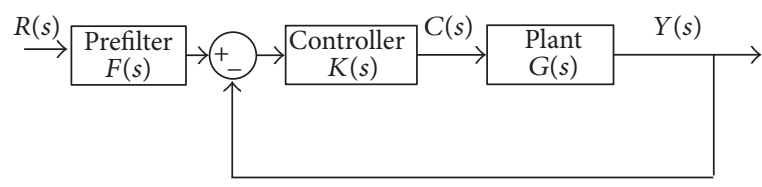

FIGURE 3: Schematic representation of 2-DoF QFT Configuration.

stability, and so on are satisfied and these objectives have to be declared on the onset of design procedure [46]. QFT uses two-degree of freedom (2-DoF) control configuration, in which one controller $K(s)$ is in the feedback loop and is meant for reducing the closed loop uncertainties and the other controller is the prefilter $F(s)$ which is present prior to the loop in feed-forward configuration which is meant for shaping the input so that the desired output is obtained. The 2-DoF structure is shown in Figure 3.

In QFT the plant uncertainty is depicted by templates, which give us a measure of if the controller design is possible or not. The system specifications are converted into bounds for each design frequency on the onset of design procedure and in the loop shaping stage, the nominal open loop transfer function $L_{o}$ must satisfy them. The loop shaping stage is performed on the Nichols chart on which the QFT bounds acts as guiding lines for the designing the controllers such that all the bounds are satisfied at each frequency of interest and has minimal high-frequency gain. In manual design process, poles and zeros are added to the controller $K(j \omega)$ such that $L_{o}$ satisfies the QFT bounds. Generally, the controller is shown by equation as follows:

$$
\begin{aligned}
& K(s) \\
& \quad=K_{G} \frac{\prod_{i=1}^{m_{1}}\left(s+z_{i}\right) \prod_{i=1}^{m_{2}}\left(s^{2}+2 \xi_{a i} \omega_{a i} s+\omega_{a i}{ }^{2}\right)}{s^{n_{1}}\left(s+p_{i}\right) \prod_{i=1}^{n_{2}}\left(s^{2}+2 \xi_{b i} \omega_{b i} s+\omega_{b i}{ }^{2}\right)},
\end{aligned}
$$

where $K_{G}$ is the controller gain, there are $m_{1}$ real zeros $z_{i}$ and $n_{1}$ real poles $p_{i}$ and $2 m_{2}$ complex zeros and $2 n_{2}$ complex poles, and $\gamma$ is the order.

\section{Introduction to TLBO}

Teaching learning-based optimization (TLBO) has been introduced by Rao et al. [33] in 2011. TLBO imbibes the 
phenomenon of teaching and learning and has the essence that the teacher influences the performance of the learners in a class. The algorithm has been divided into two phases, which mimics the ability of teaching learning of the teacher and students. The two phases are (a) teacher phase and (b) learner phase. There are two ways by which the pupils can learn, that is, one through direct interaction with the teacher, who is a highly learned being, and the other through the pupils' interaction among themselves, which also improve the results. The measure of learning is given by the grades and teacher directly influences grades. TLBO is a populationbased algorithm, where $n$ is the number of learners (population size), $m$ is the different subject the pupil has to learn (dimension of the optimization problem), and the teacher is considered as the best solution amongst all solutions. The teaching and learning phases of TLBO are discussed as follows.

5.1. Teacher Phase. The teacher is a highly learned being and in the first phase of TLBO, the learners learn from the teacher. The teacher imparts knowledge to the learners and tries to increase their knowledge (mean result) in the subject being taught. In this phase, a random population is generated, and the point, which has the minimum value of fitness function, is chosen as the teacher. The chosen teacher shares that information with the learners. The teaching is said to be significant if the mean results of the class increase (let us assume the mean result increases from $M_{A}$ to $M_{B}$ ). The best teacher is the one who tries to bring the level of students up to its level [33]; but it is not possible, as it depends upon the capability of the learners, as the teacher can only increase the mean result of the class. The number of variables $n$ on the optimization decides the number of teachers and subjects.

The value of teaching factor can either be 1 or 2 and is chosen randomly with an equal probability as given in (17) [33]. The difference mean is given by (18). Suppose that mean result is $M_{I}$ and teacher is $T_{i}$ at any iteration $i$; the teacher $T_{i}$ tries to improve the mean by converging it towards its own level and the new mean is given by $M_{\text {new }}$ [33]. The new solution $X_{\text {new }}$ is generated by adding the difference means as given by (19).

$$
\begin{aligned}
& T_{F}=\operatorname{round}[1+\operatorname{rand}(0,1)\{2-1\}], \\
& \text { Diff_Mean }{ }_{i}=r_{i}\left(M_{\text {new }}-T_{F} M_{i}\right), \\
& X_{\text {new }, i}=X_{\text {old }, i}+\text { Diff_Mean } \\
&
\end{aligned}
$$

where $T_{F}$ is the teaching factor and influences the mean to be changed. $r_{i}$ is the random number generated within $[0,1]$.

5.2. Learner Phase. The second phase of TLBO comprises increasing the knowledge through the mutual learning among the learners; that is, from the population any learner randomly interacts with some other member in the class to learn something new. The learning will happen only when the other member has more knowledge than the latter. Equations (20a) and (20b) give the mathematical expression for the learning phase as [33] for two learners $X_{i}$ and $X_{j}$, where $i \neq j$ :

$$
\begin{array}{ll}
X_{\mathrm{new}, i}=X_{\mathrm{old}, i}+r_{i}\left(X_{i}-X_{j}\right), & \\
& \text { if } f\left(X_{i}\right)<f\left(X_{j}\right), \\
X_{\text {new }, i}=X_{\mathrm{old}, i}+r_{i}\left(X_{j}-X_{i}\right), & \\
& \text { if } f\left(X_{i}\right)>f\left(X_{j}\right),
\end{array}
$$

where $f\left(X_{i}\right)$ and $f\left(X_{j}\right)$ are the fitness of the chosen two learners.

The new solution is accepted only when it minimizes or maximizes the objective function. As the teaching learning progresses, the level (mean) of knowledge of learners shifts towards that of the teacher and the algorithm converges towards a solution. The TLBO algorithm is shown in Figure 4.

\section{Automating Loop Shaping of QFT Controller for PMSM Using TLBO}

Manual loop shaping of QFT controller is a tedious and time-consuming task even for an expert designer and there is no guarantee that an optimal controller is obtained. The automatic loop shaping of the QFT controller aims at designing an optimal controller automatically such that all the predefined performances of robustness, tracking, robust stability, and so on are achieved. Automatic loop shaping is performed directly on $L_{0}(j \omega)$ which directly follows the essence of QFT design procedure. Closed loop response is represented by $T(j \omega)$ and open loop transmission by $L(j \omega)$ and is given by

$$
\begin{aligned}
|T(j \omega)| & =\left|\frac{L(j \omega)}{1+L(j \omega)}\right|, \\
L(j \omega) & =K(j \omega) G(j \omega) .
\end{aligned}
$$

In this paper, QFT controller is designed for minimizing the variations in the closed loop response due to parametric uncertainty and the response of the system to external noise. So the objectives of robust stability and sensitivity reduction have been considered for the automatic design process. Minimization of the sensitivity has been chosen for the frequency range of 0 to $10 \mathrm{rad} / \mathrm{sec}$ and for good disturbance rejection and is given by (23). The TLBO algorithm-specific parameters chosen in the design process are as follows: class size of 50, dimension of the problem of 3 , and maximum number of iterations of 1000 .

$$
|S(j \omega)|=\left|\frac{1}{1+L(j \omega)}\right| .
$$




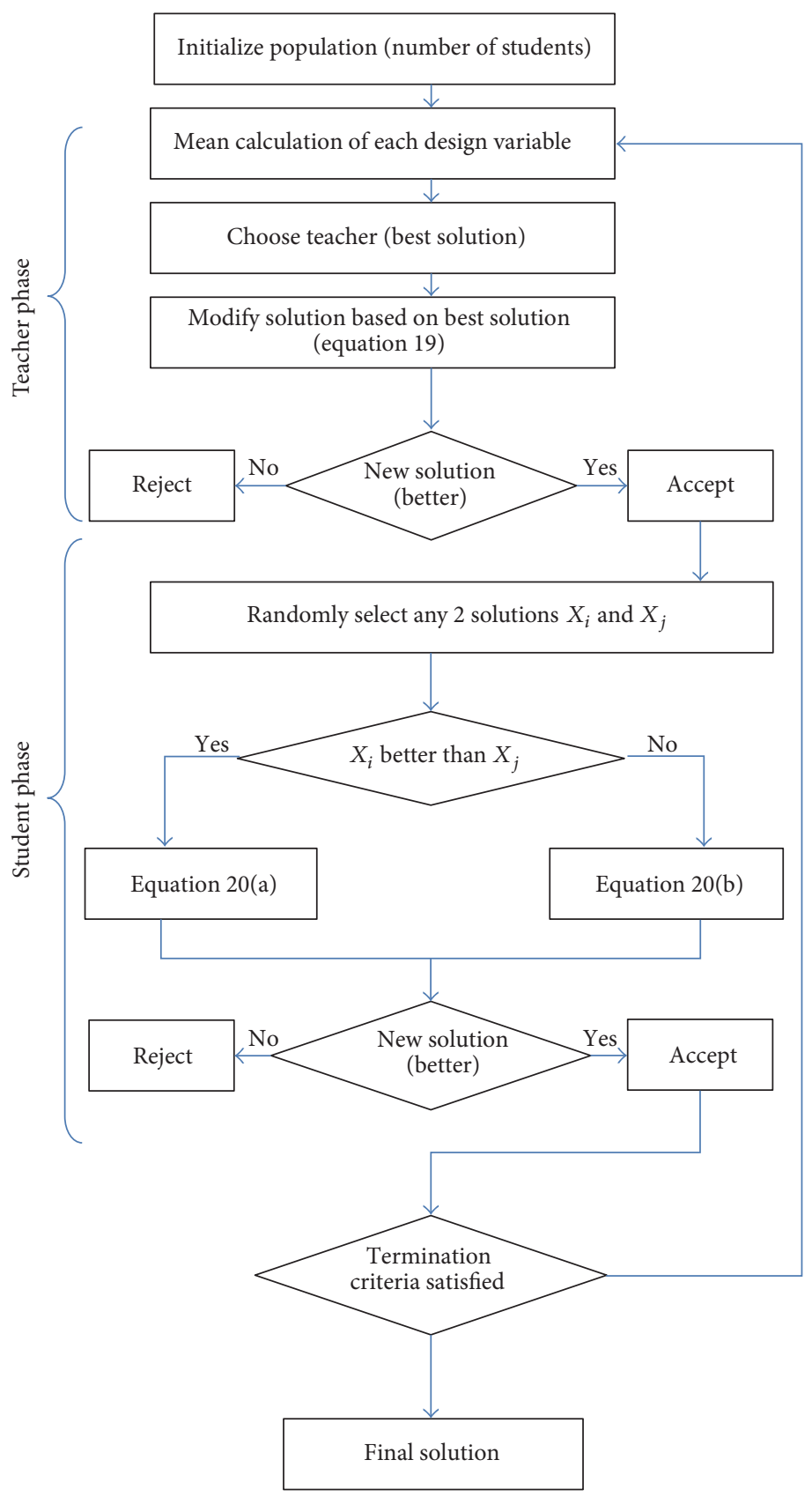

FIGURE 4: Flow chart of teaching learning-based optimization algorithm.

So the QFT controller designed must ensure robust stability, tracking, and disturbance rejection. These specifications act as guides for designing the controller by shaping the nominal open loop transmission $L_{0}(j \omega)$. The design specifications considered in the design for the sensitivity and complementary sensitivity functions are given by

$$
|T(j \omega)|=\left|\frac{L(j \omega)}{1+L(j \omega)}\right| \leq 1.2,
$$

$$
|S(j \omega)|=\left|\frac{1}{1+L(j \omega)}\right| \leq 1.2 .
$$

In the design process, TLBO has been used for designing the QFT controller for a 2-phase PMSM such that the designed closed loop system offers a robust response. The specifications of complementary sensitivity and sensitivity have been chosen as the performance index and been expressed as the weighted objective function whose minimization has been considered for designing the optimal controller. The weighted objective function $J_{K}$ is given by (25). In the design 
process, a PID controller has been chosen (see (26)) and the minimization of $J_{K}$ using TLBO aims at finding the optimal values of controller gains $K_{p}, K_{i}$, and $K_{d}$ such that the design specifications are satisfied. The minimization of $J_{K}$ minimizes the magnitude of the sensitivity function and complementary sensitivity over a chosen discrete frequency range and this automatically designs a controller, which satisfies the desired QFT specifications.

$$
\begin{aligned}
J_{K} & =\min \left(|T(j \omega)|+\left|W_{P} \cdot S(j \omega)\right|\right), \\
K(s) & =K_{p}+\frac{K_{i}}{s}+K_{d} s,
\end{aligned}
$$

where $W_{p}$ is the weighting function and has been chosen such that the sensitivity is reduced for the frequency range of 0 to $10 \mathrm{rad} / \mathrm{sec}$ and is given by

$$
W_{P}=\frac{0.5 s+10}{s+0.1} \text {. }
$$

\section{Results and Discussions}

In this design example, for designing the QFT based controller $K(s)$, a fixed order controller (PID) has been chosen and is given by (26). The nominal case of the plant $G_{0}(s)$ considered for shaping the $L_{0}(j \omega)$ is given by (15). The objective function $J_{K}$ given by (25) has been expressed as aggregate of function (AOF) and is minimized to obtain the optimal controller values. Reduction of the sensitivity $S(j \omega)$ ensures good tracking performance and the minimization of complementary sensitivity $T(j \omega)$ ensures good noise rejection. The use of sensitivity and robust stability criteria for forming the objective function automatically follows the QFT process and the obtained optimal controller is obtained that satisfies the design objectives.

The TLBO shapes the open loop transmission function (see (28)) such that an optimal QFT controller is obtained. The algorithm evaluates the function value at all the design frequencies taken as $\omega=[0.4,0.8,1.2,1.7,2.1,10,25$, $50,100,200]$.

$$
\begin{aligned}
L_{0}(s)= & \left\{K_{p}+\frac{K_{i}}{s}+K_{d} s\right\} \\
& \cdot \frac{350}{s^{3}+15.04 \cdot s^{2}+177.8 \cdot s+378} .
\end{aligned}
$$

Automatic loop shaping of the QFT controller using TLBO has been done in the Matlab to obtain the optimal values of 3 parameters of $\left[K_{p}, K_{i}, K_{d}\right]$. The optimal QFT controller obtained by the automated loop shaping using TLBO is given by

$$
K_{\mathrm{TLBO}}(s)=0.65163+\frac{1.3052}{s}+0.0154 \cdot s .
$$

The obtained controller in (28) has been used in the closed loop configuration in the system. In order to test the efficacy of the TLBO tuned QFT controller, a comparison has been made against QFT controller designed using other

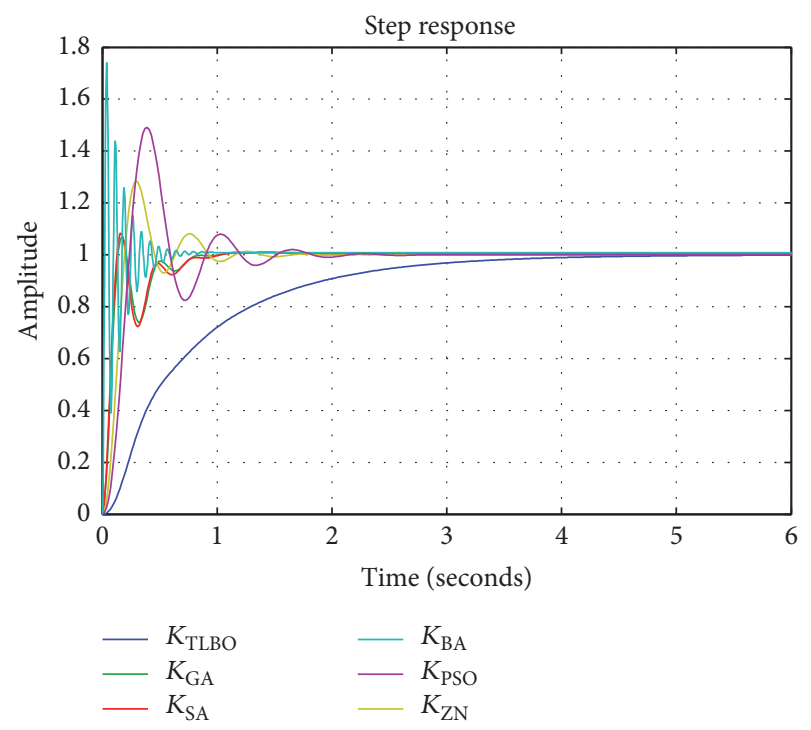

FIgURE 5: Compared closed loop step response of the PMSM (nominal case) with TLBO, GA, SA, BA, and PSO tuned QFT controller and Ziegler Nichols tuned PID controller.

optimization algorithms like GA, SA, bat algorithm, and PSO and classical PID tuning methods like Ziegler Nichols $(\mathrm{ZN})$. The controllers obtained by genetic algorithm $K_{\mathrm{GA}}(s)$, simulated annealing $K_{\mathrm{SA}}(s)$, bat algorithm $K_{\mathrm{BA}}(s)$, particle swarm optimization $K_{\mathrm{PSO}}(s)$, and Zeigler Nichols $K_{\mathrm{ZN}}(s)$ are given by

$$
\begin{aligned}
& K_{\mathrm{GA}}(s)=4.334+\frac{9.274}{s}+0.792 \cdot s, \\
& K_{\mathrm{SA}}(s)=4.448+\frac{9.259}{s}+0.885 \cdot s, \\
& K_{\mathrm{BA}}(s)=31.8176+\frac{220.046}{s}+19.499 \cdot s, \\
& K_{\mathrm{PSO}}(s)=2.8175+\frac{16.8086}{s}+0.0919 \cdot s, \\
& K_{\mathrm{ZN}}(s)=4.01+\frac{16.41}{s}+0.2406 \cdot s .
\end{aligned}
$$

The compared step response of closed loop system for the nominal plant transfer function has been shown in Figure 5. From Figure 5, it can be seen that the response of all the other controllers except $K_{\mathrm{TLBO}}(s)$ is very oscillatory with very large overshoot percentages. Thus the response offered by the TLBO tuned QFT controller is much efficient in terms of time response of the system as can be seen numerically in Table 2. From Table 2, looking at the time domain specifications only the TLBO tuned QFT controller offers $0 \%$ overshoot percentage and the response is also not oscillatory, while the time domain response of the other designed controllers is highly oscillatory with very high overshoot percentages.

The compared frequency response of the closed loop system has been shown in Figure 6(a) and it can be seen that the frequency response offered by the TLBO tuned QFT controller has zero peak for the closed loop system 
TABLE 2: Time domain indices of closed loop system for nominal plant.

\begin{tabular}{|c|c|c|c|c|c|c|}
\hline Time domain performance index & $K_{\mathrm{TLBO}}(s)$ & $K_{\mathrm{GA}}(s)$ & $K_{\mathrm{SA}}(s)$ & $K_{\mathrm{BA}}(s)$ & $K_{\mathrm{PSO}}(s)$ & $K_{\mathrm{ZN}}(s)$ \\
\hline Rise time (sec) & 1.768 & 0.091 & 0.085 & 0.013 & 0.144 & 0.173 \\
\hline Settling time (sec) & 3.415 & 0.754 & 0.749 & 0.572 & 1.674 & 1.1 \\
\hline Overshoot percentage (\% age) & 0 & 6.93 & 8.296 & 73.953 & 49.099 & 28.9 \\
\hline Steady state error (\% age) & 0 & 0 & 0 & 0 & 0 & 0 \\
\hline Gain margin $(\mathrm{dB})$ & 22.2 & 151 & 7.13 & 146 & 7.13 & 19.3 \\
\hline Phase margin (deg) & 90.6 & 43.2 & 41.2 & 9.38 & 31 & 43.2 \\
\hline Peak response $|S(j \omega)|(\mathrm{dB})$ & 1.18 & 22.3 & 5.13 & 15.7 & 8.8 & 6.19 \\
\hline Peak response $|T(j \omega)|(\mathrm{dB})$ & $\approx 0$ & 2.75 & 3.12 & 15.7 & 6.01 & 3.37 \\
\hline
\end{tabular}

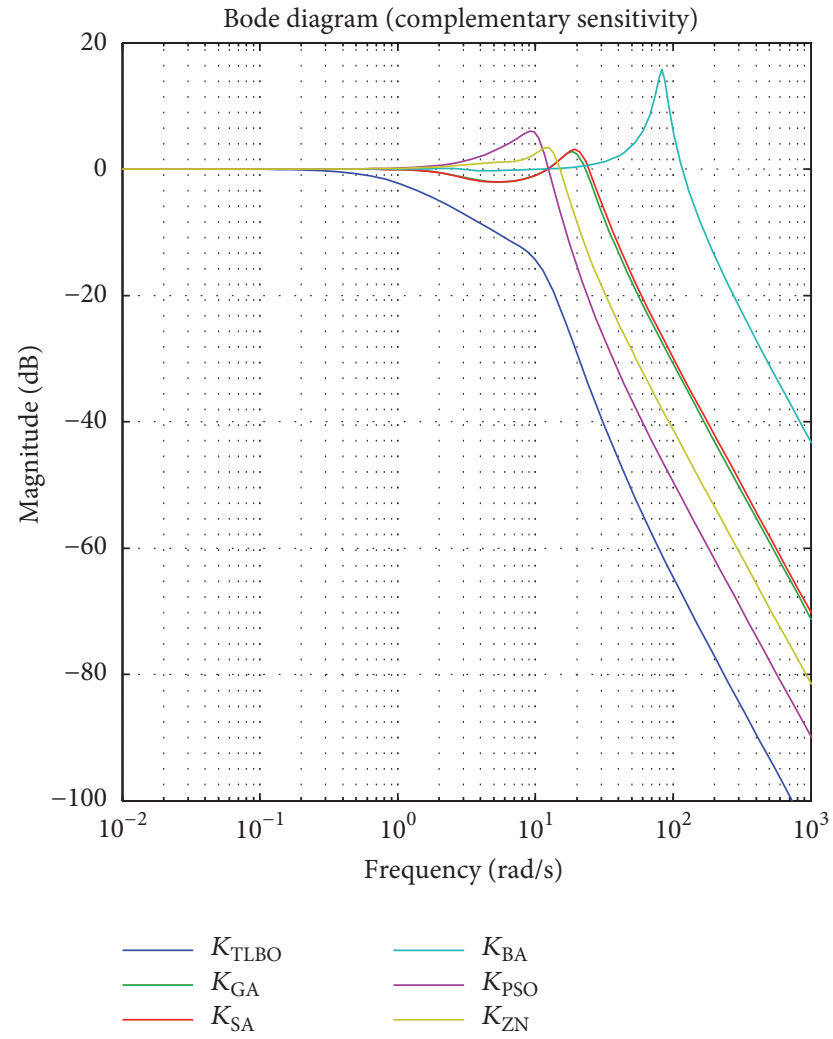

(a)

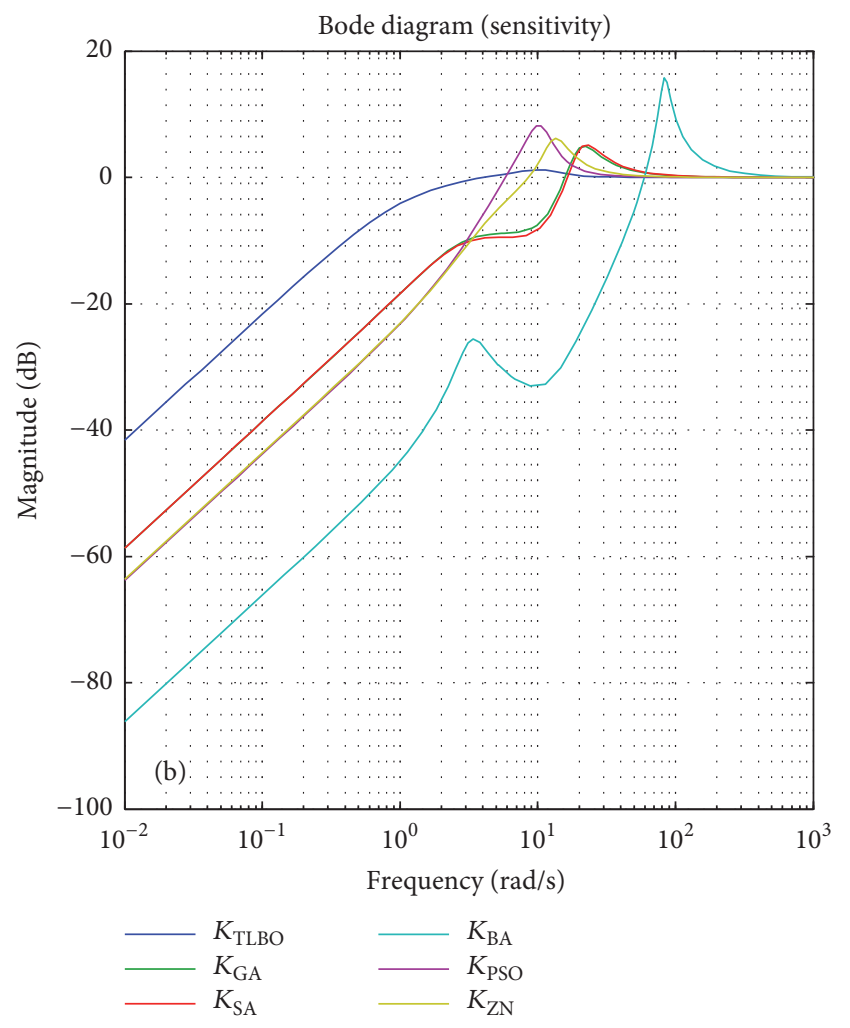

(b)

FIGURE 6: Compared frequency response of the PMSM (nominal case) with TLBO, GA, SA, BA, and PSO tuned QFT controller and Ziegler Nichols tuned PID controller.

at all frequencies, whereas the peak response of the closed loop systems is very high and does not satisfy the design requirements as given in (24a) as can be seen in Table 2 . Similarly, for the sensitivity function (Figure 6(b)), the peak response offered by TLBO tuned QFT controller lies within the design criterion, while the peak response offered by other designed controllers is very high and does not adhere to the design requirements.

Nichols chart for the open loop transmission with the controllers obtained is shown in Figure 7, and from the figure it can be seen that all the systems are stable in their closed loop configuration. The various frequency domain characteristics are given in Table 2. Any disturbance inserted before the plant has to be minimized to zero; Figure 8 shows the plot for input disturbance rejection for the nominal plant. However, all the designed controllers efficiently eliminate it completely and also offer better closed loop set-point tracking.

\section{Design Validation}

In order to validate the efficiency of the TLBO tuned QFT controller, so it can easily handle the parametric uncertainty in the PMSM, worst-case closed loop response of the system has been considered. The parametric variation in the nominal PMSM parameters has been taken as $\pm 10 \%$ and $\pm 40 \%$ of nominal value (as in Table 1) [43]. 


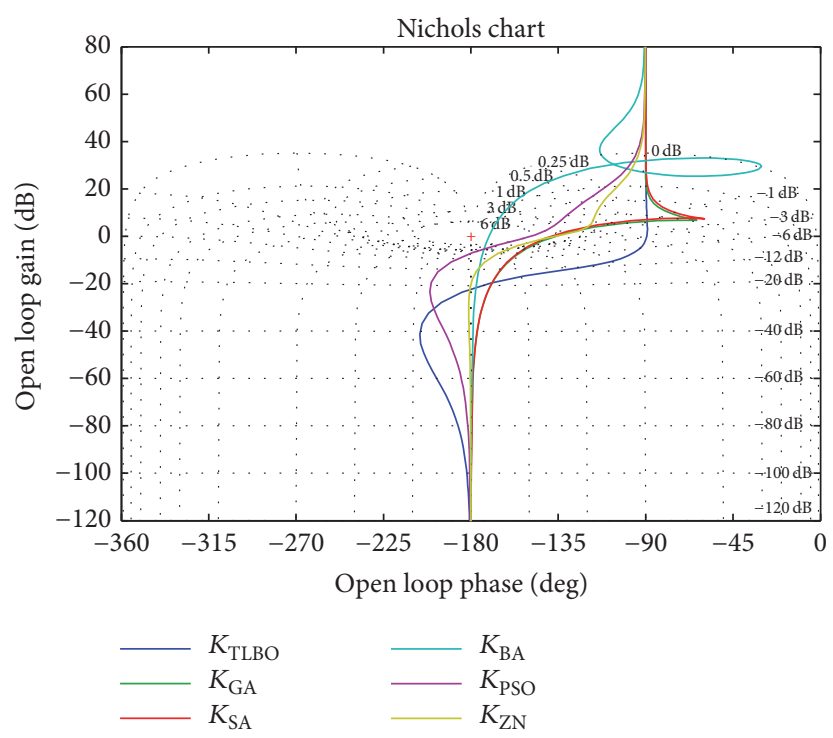

FIgURE 7: Compared Nichols chart for the PMSM (nominal case) with TLBO, GA, SA, BA, and PSO tuned QFT controller and Ziegler Nichols tuned PID controller.

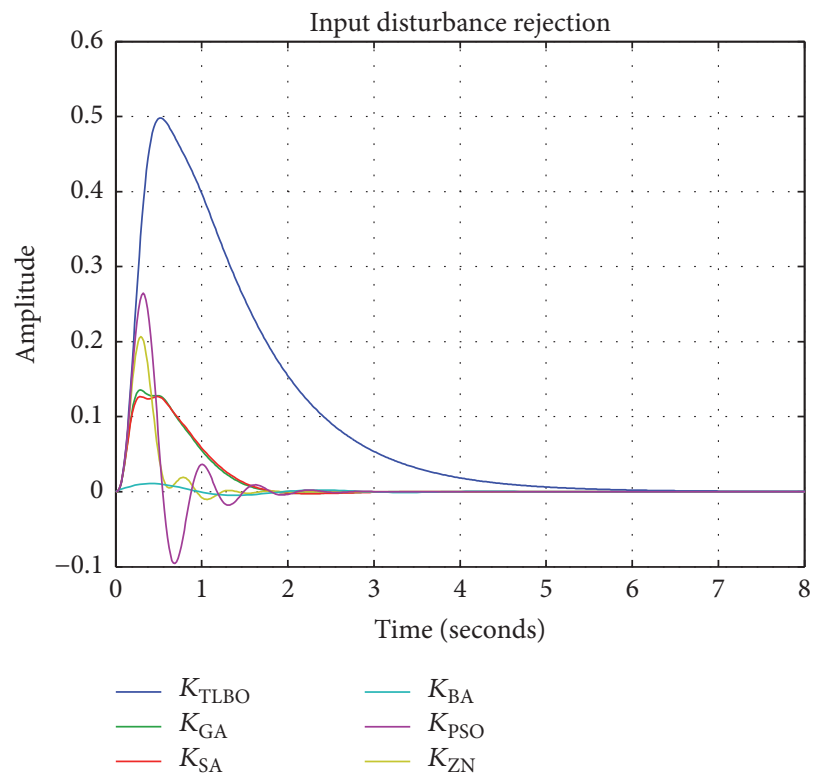

FIGURE 8: Compared input disturbance rejection by the PMSM (nominal case) with TLBO, GA, SA, BA, and PSO tuned QFT controller and Ziegler Nichols tuned PID controller.

8.1. Plant with $\pm 10 \%$ Uncertainty. The designed controller must be able to handle such uncertainties efficiently and force the system to its desired set point. The closed loop step response of the system considering $\pm 10 \%$ uncertainties has been shown in Figure 9 and from the figure it can be seen that the designed QFT controller eminently handles all the parametric uncertainties, efficiently tracks the step input, and still offers $0 \%$ overshoot percentage, while the other designed controllers offer a very oscillatory response as can be seen in Figure 9 and the values of overshoot percentage are also very high. Another significant deduction can be established from Figure 9 that, considering the range of $\pm 10 \%$ parametric uncertainties, the TLBO tuned QFT controller stabilizes the system in a very narrow envelope; that is, in case of any uncertainty the output of the PMSM will not be drastically affected and will remain almost the same. Table 3 shows the worst-case time and frequency domain performance parameters that will be obtained in case of parametric uncertainty in the system.

Figure 10 shows the plot for the input disturbance rejection for the PMSM in presence of parametric uncertainties and it can be seen that all the designed controllers successfully minimize it to zero. The magnitude plot for frequency response of the system with parametric uncertainties is shown in Figure 11 and it can be seen that the TLBO tuned QFT controller provides a very narrow variation along the 


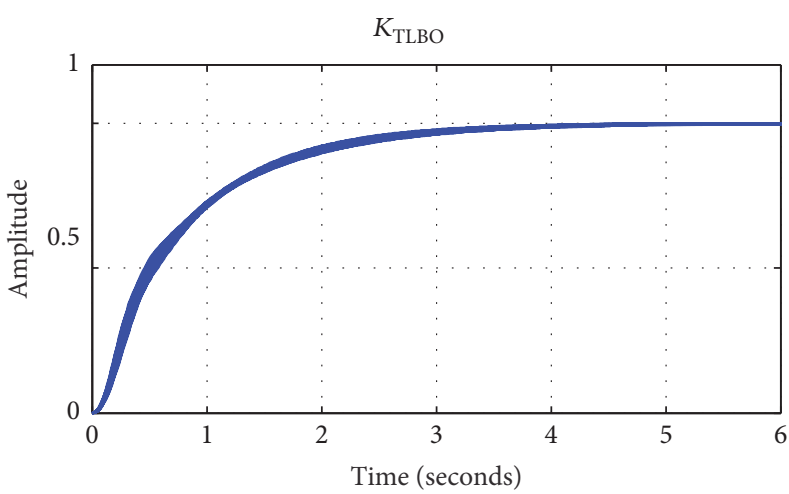

(a)

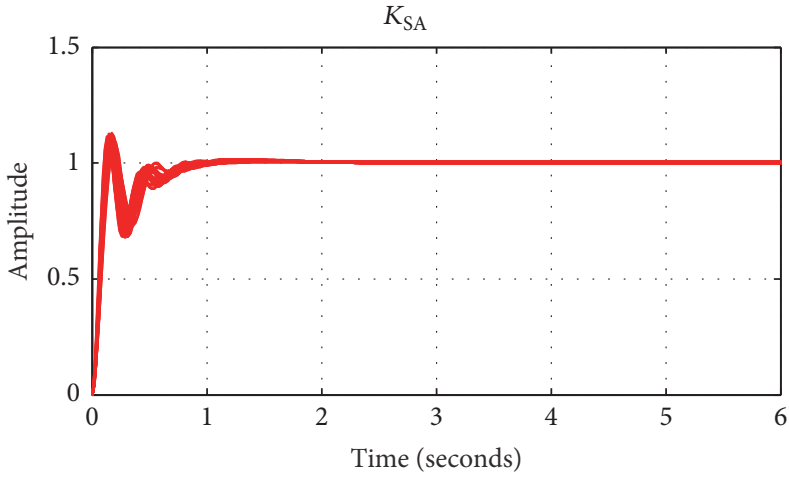

(c)

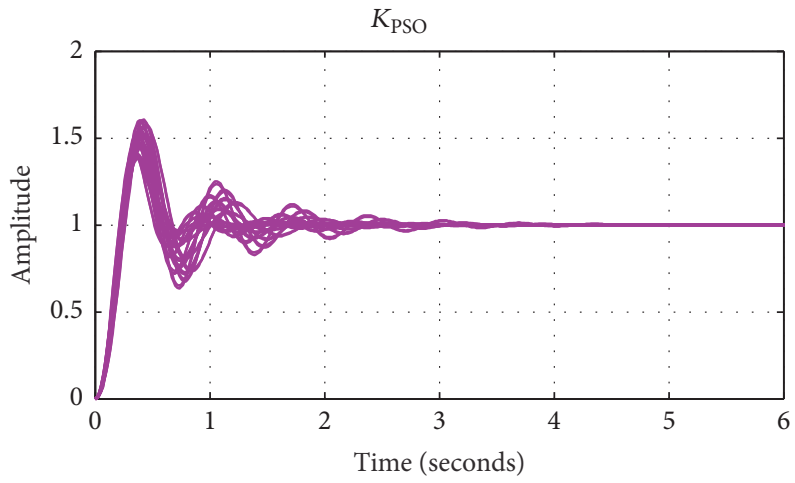

(e)

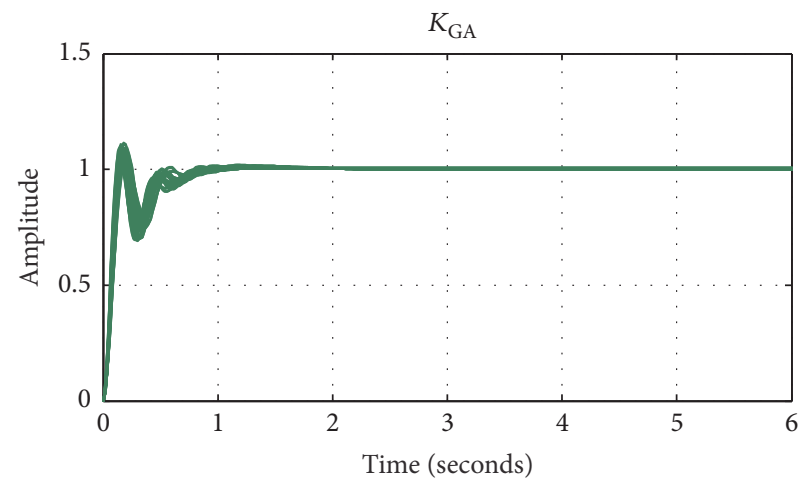

(b)

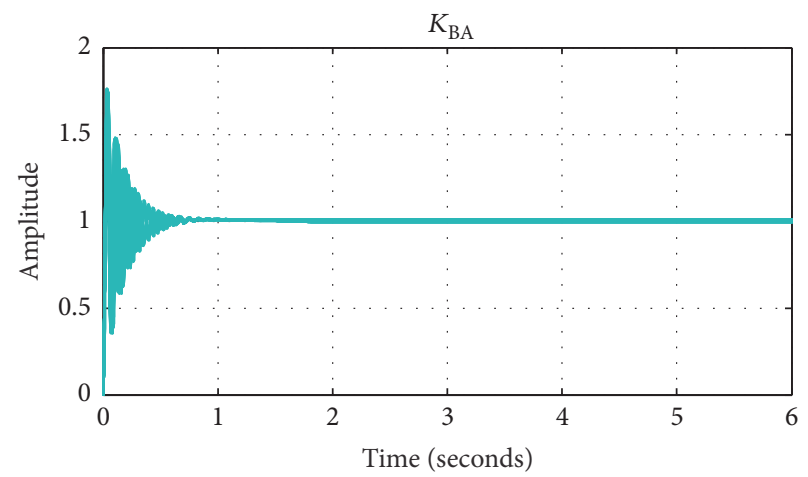

(d)

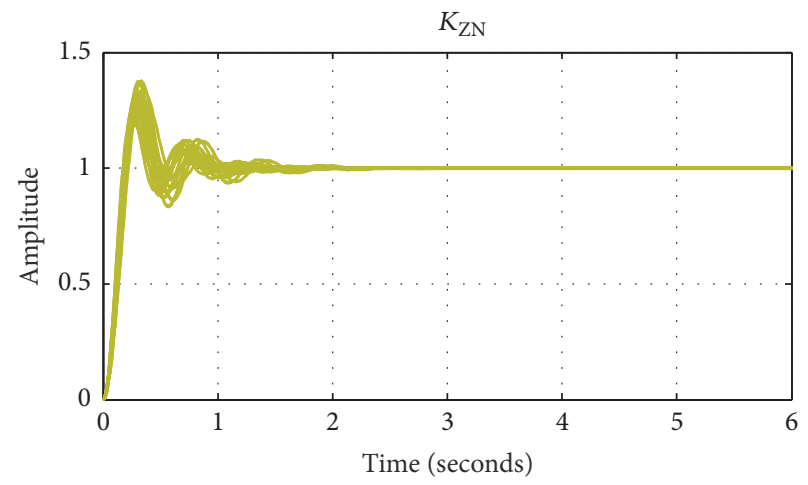

(f)

FIGURE 9: Compared closed loop step response of the uncertain PMSM ( $\pm 10 \%$ uncertainty range) with TLBO, GA, SA, BA, and PSO tuned QFT controller and Ziegler Nichols tuned PID controller.

TABLE 3: Performance indices of closed loop system for worst-case plant scenario ( $\pm 10 \%$ uncertainty range).

\begin{tabular}{|c|c|c|c|c|c|c|}
\hline Performance index ( $\pm 10 \%$ uncertainty range) & $K_{\mathrm{TLBO}}(s)$ & $K_{\mathrm{GA}}(s)$ & $K_{\mathrm{SA}}(s)$ & $K_{\mathrm{BA}}(s)$ & $K_{\mathrm{PSO}}(s)$ & $K_{\mathrm{ZN}}(s)$ \\
\hline Rise time (sec) & 1.7731 & 0.0926 & 0.0864 & 0.0128 & 0.1561 & 0.1371 \\
\hline Settling time (sec) & 3.479 & 0.799 & 0.7852 & 0.618 & 2.891 & 1.7093 \\
\hline Overshoot percentage (\%) & 0 & 11.54 & 13.027 & 76.35 & 60.47 & 37.854 \\
\hline Steady state error $\%$ age (\%) & 0 & 0 & 0 & 0 & 0 & 0 \\
\hline Gain margin $(\mathrm{dB})$ & 20.2 & 149 & 6.85 & 144 & 4.3 & 11.6 \\
\hline Phase margin (deg) & 86.2 & 37.2 & 35.6 & 8.31 & 19.2 & 30.9 \\
\hline Peak values $T(j \omega)(\mathrm{dB})$ & $\approx 0$ & 3.42 & 4.22 & 16.7 & 10.5 & 6.09 \\
\hline Peak values $S(j \omega)(\mathrm{dB})$ & 1.19 & 5.66 & 5.85 & 16.7 & 12 & 8.01 \\
\hline
\end{tabular}




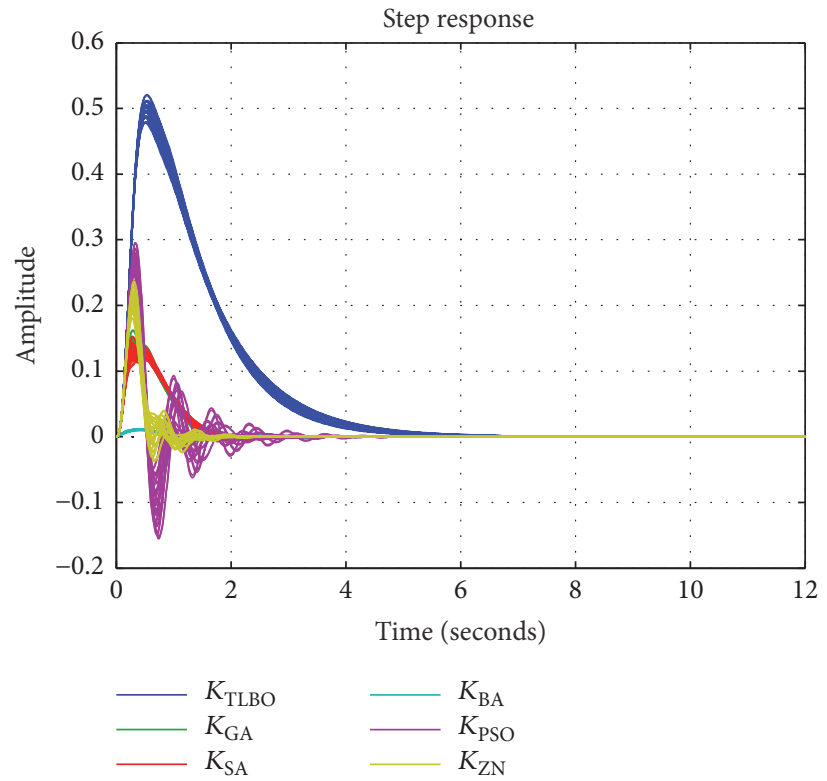

FIGURE 10: Compared plot for input disturbance rejection by the uncertain PMSM ( $\pm 10 \%$ uncertainty range) with TLBO, GA, SA, BA, and PSO tuned QFT controller and Ziegler Nichols tuned PID controller.

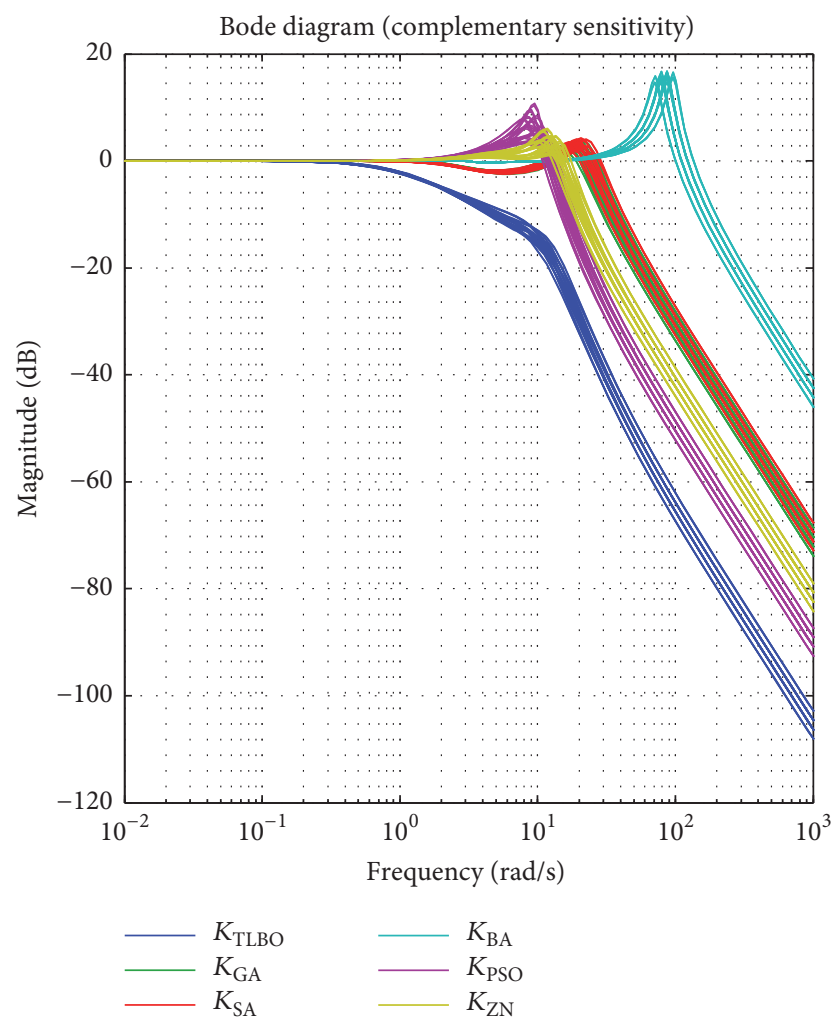

(a)

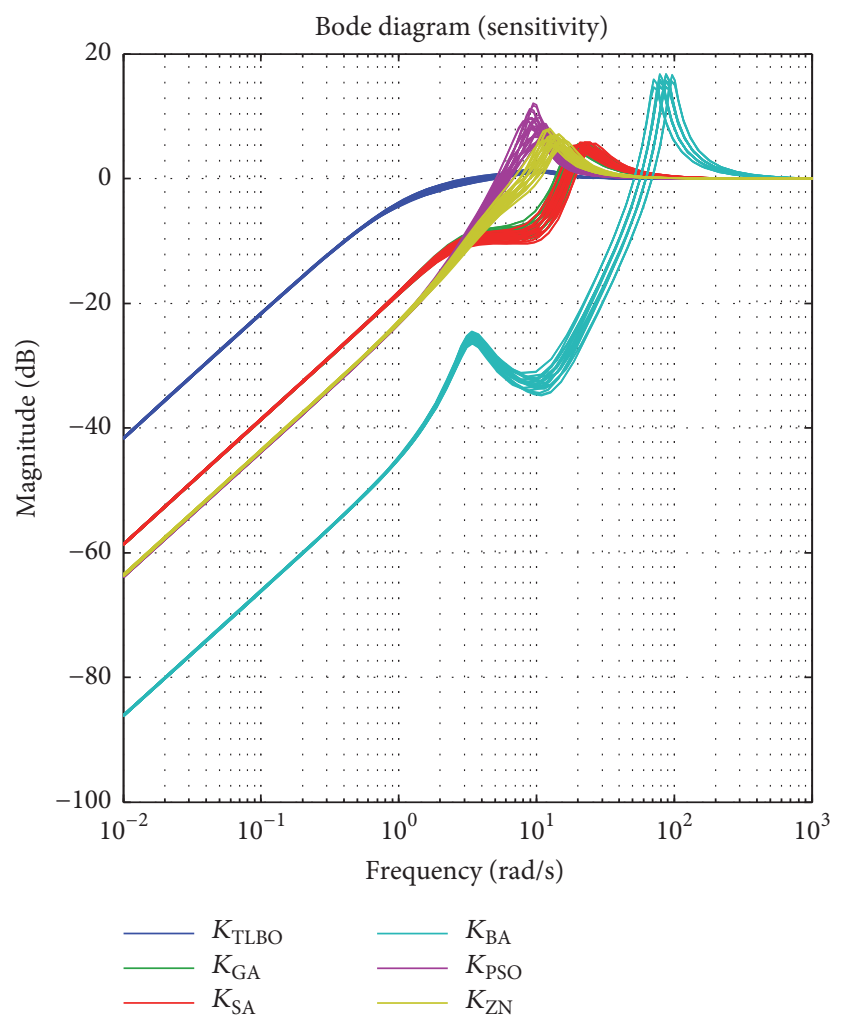

(b)

Figure 11: Compared frequency response of the uncertain PMSM ( $\pm 10 \%$ uncertainty range) with TLBO, GA, SA, BA, and PSO tuned QFT controller and Ziegler Nichols tuned PID controller. 


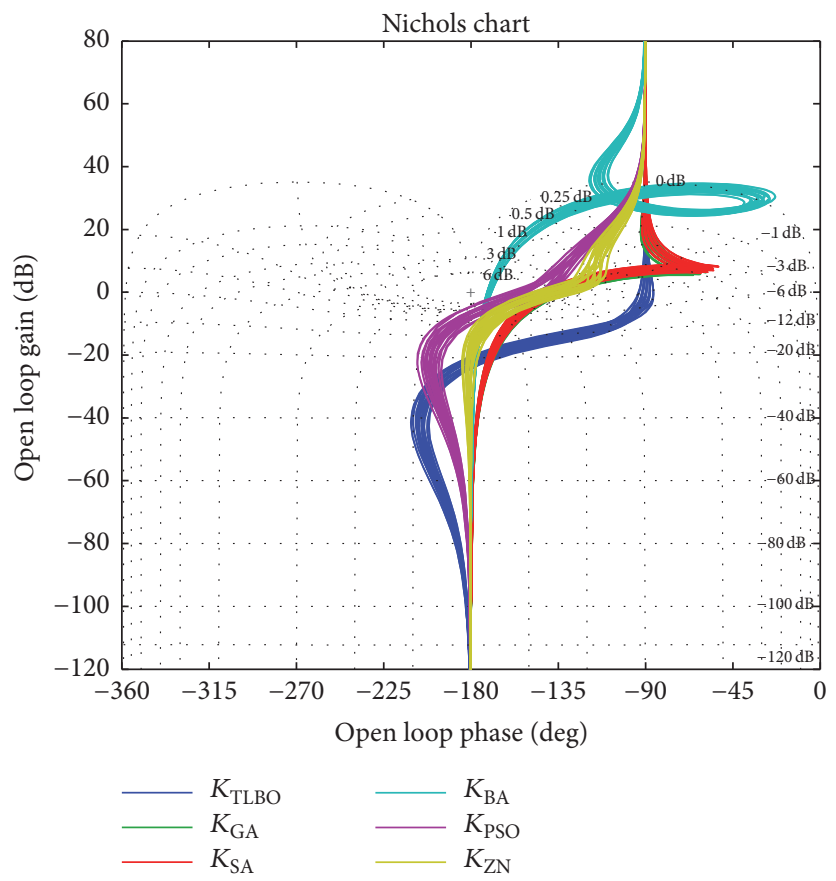

FIGURE 12: Compared Nichols chart for the open loop transmission $L_{0}(j \omega)$ of the uncertain PMSM $( \pm 10 \%$ uncertainty range) with TLBO, GA, SA, BA, and PSO tuned QFT controller and Ziegler Nichols tuned PID controller.

TABle 4: Performance indices of closed loop system for worst-case plant scenario ( $\pm 40 \%$ uncertainty range).

\begin{tabular}{|c|c|c|c|c|c|c|}
\hline Performance index ( $\pm 40 \%$ uncertainty range) & $K_{\text {TLBO }}(s)$ & $K_{\mathrm{GA}}(s)$ & $K_{\mathrm{SA}}(s)$ & $K_{\mathrm{BA}}(s)$ & $K_{\mathrm{PSO}}(s)$ & $K_{\mathrm{ZN}}(s)$ \\
\hline Rise time (sec) & 1.268 & 0.102 & 0.0973 & 0.0111 & $\infty$ & 0.176 \\
\hline Settling time (sec) & 3.49 & 1.005 & 0.9672 & 0.8658 & $\infty$ & 36.83 \\
\hline Overshoot percentage (\%) & 2.85 & 25.36 & 25.23 & 82.32 & $\infty$ & 73.28 \\
\hline Steady state error $\%$ age (\%) & 0 & 0 & 0 & 0 & $\infty$ & 0 \\
\hline Gain margin $(\mathrm{dB})$ & 14.3 & 145 & 6.76 & 138 & -4.09 & 0.551 \\
\hline Phase margin (deg) & 68.9 & 23 & 22.3 & 5.62 & -16.5 & 1.63 \\
\hline Peak values $T(j \omega)$ & $\approx 0$ & 8.01 & 8.5 & 20.2 & 28.6 & 31.4 \\
\hline Peak values $S(j \omega)$ & 1.56 & 8.85 & 9.04 & 20.3 & 28.7 & 31.5 \\
\hline
\end{tabular}

nominal plant for which the controller has been designed and the values lie within the design norms.

Compared Nichols chart for the open loop transmission with the all the tuned QFT controllers and ZN-PID with $\pm 10 \%$ uncertainty range has been shown in Figure 12, and it can be seen in the figure that response offered by the designed TLBO tuned QFT controller lies in a very tight envelope and offers very good values of gain and phase margins as in Table 3.

8.2. Plant with $\pm 40 \%$ Uncertainty. The closed loop step response of the system considering $\pm 40 \%$ uncertainties has been shown in Figure 13 and from the figure it can be seen that the designed QFT controller eminently handles all the parametric uncertainties and efficiently tracks the step input, while the other designed controllers offered a highly oscillatory response with very high overshoot percentage (Figure 13), especially the PSO tuned QFT controller offering an unstable response (Figure 13(e)). Another significant deduction can be established from Figure 13 that, considering the range of $\pm 40 \%$ parametric uncertainties, the TLBO tuned QFT controller stabilizes the system in a very narrow envelope; that is, in case of any uncertainty the output of the PMSM will not be drastically affected and will remain almost the same. Table 4 shows the worst-case time and frequency domain performance parameters that will be obtained in case of parametric uncertainty in the system.

Figure 14 shows the plot for the input disturbance rejection for the PMSM in presence of parametric uncertainties and it can be seen that only the TLBO, GA, SA, and BA tuned controllers successfully minimize it to zero, while the $\mathrm{ZN}$ tuned controller offers an oscillatory response and takes a lot of time to reduce it to zero and the PSO offers an unstable response (exponentially increasing).

The magnitude plot for frequency response of the system with parametric uncertainties is shown in Figure 15 and it can be seen that the TLBO tuned QFT controller provides a very narrow variation along the nominal plant for which the controller has been designed and the values lie within the design norms, while, for the other controllers, very high 


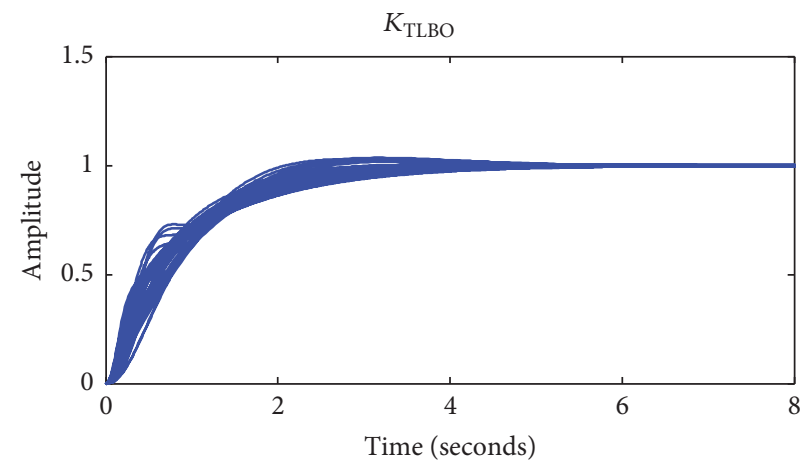

(a)

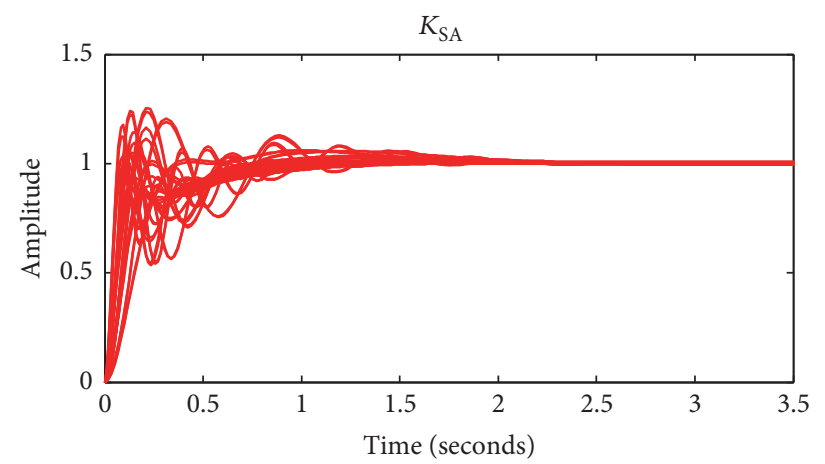

(c)

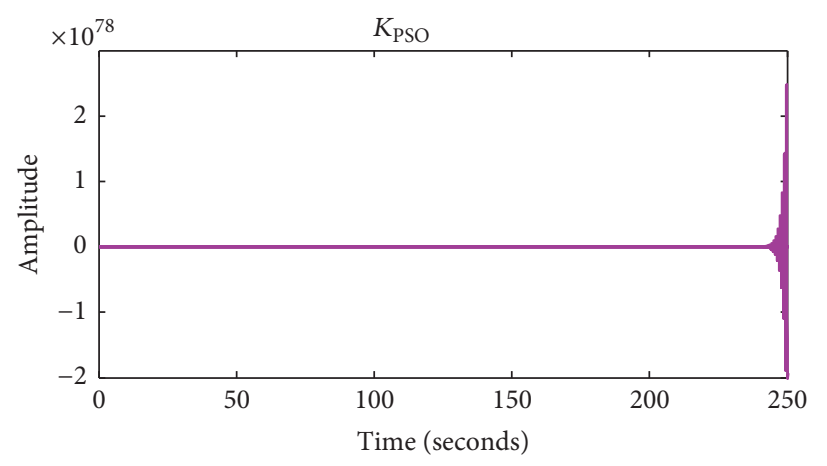

(e)

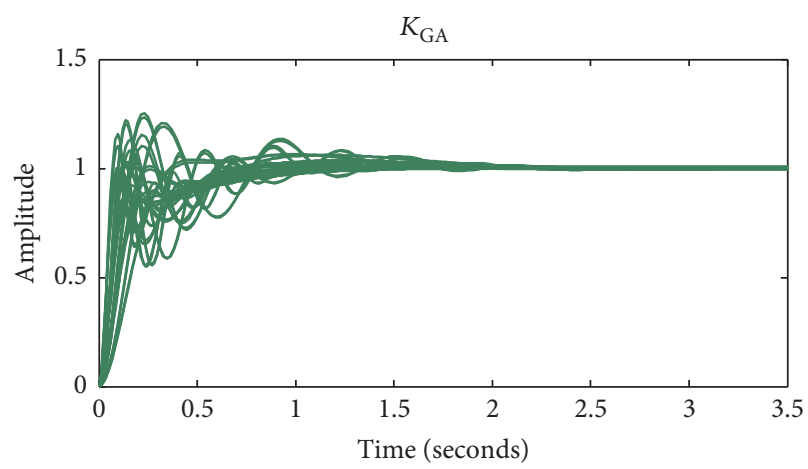

(b)

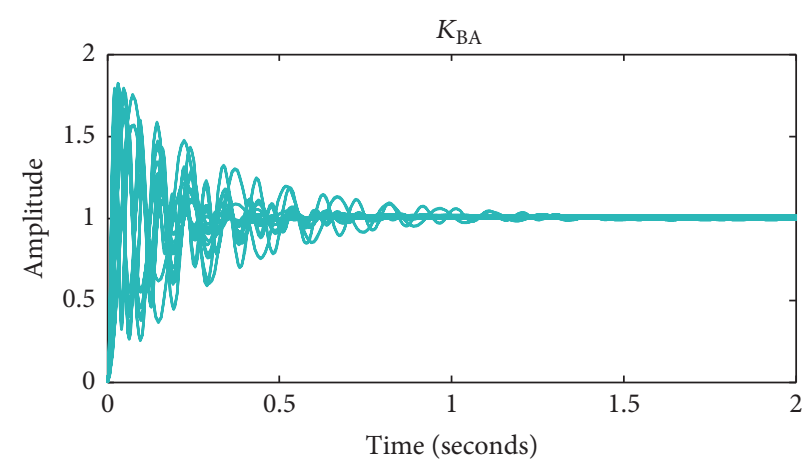

(d)

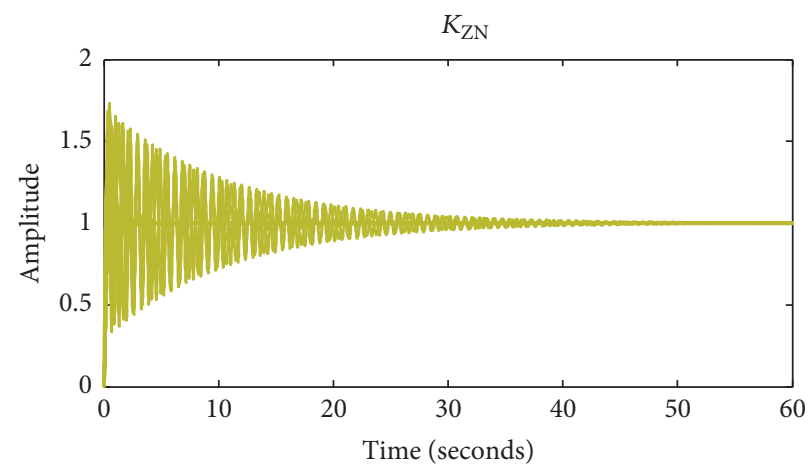

(f)

FIGURE 13: Compared closed loop step response of the uncertain PMSM ( $\pm 40 \%$ uncertainty range) with TLBO, GA, SA, BA, and PSO tuned QFT controller and Ziegler Nichols tuned PID controller.

peaks can be seen in the figure. Various frequency domain parameters are given in Table 4.

Compared Nichols chart for the open loop transmission with the all the tuned QFT controllers and ZN tuned PID with $\pm 40 \%$ uncertainty range has been shown in Figure 16, and it can be seen in the figure that response offered by the designed TLBO tuned QFT controller lies in a very tight envelope and offers very good values of gain and phase margins as in Table 4.

Figures 9-16 clearly show that the designed TLBO tuned QFT controller for PMSM system shows a satisfactory response in both time and frequency domain and designed control system also offers robust response to the \pm 10 and $\pm 40 \%$ range of parametric uncertainties. Thus, with the continuous operation of PMSM over time, there will be no significant difference on the output of the system.

\section{Conclusions}

Long and continuous operation of PMSM leads to the spawning of parametric uncertainties in the system and this makes it strenuous for the control system to exert quality control over time; this drastically impacts process safety and quality of products. This paper proposes the use of automatic loop shaping for the controller synthesis for robust positioning control of a 2-phase permanent magnet stepper motor using TLBO. TLBO deals with finding the optimal values of the 


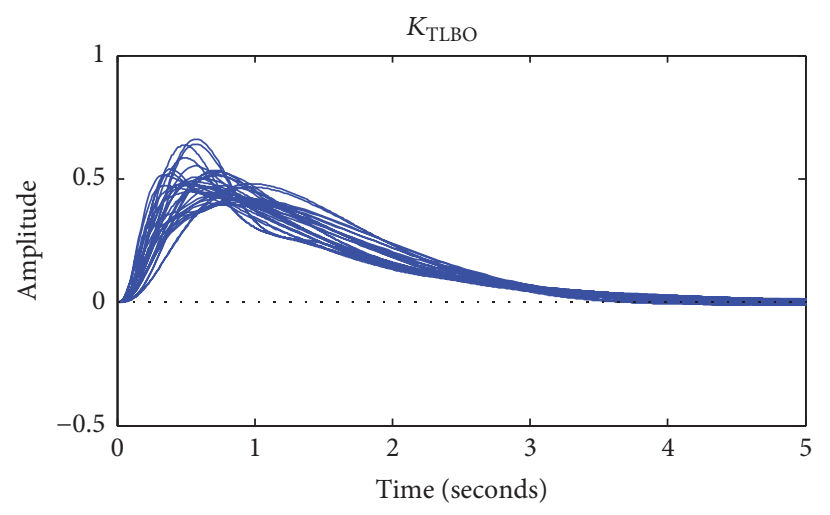

(a)

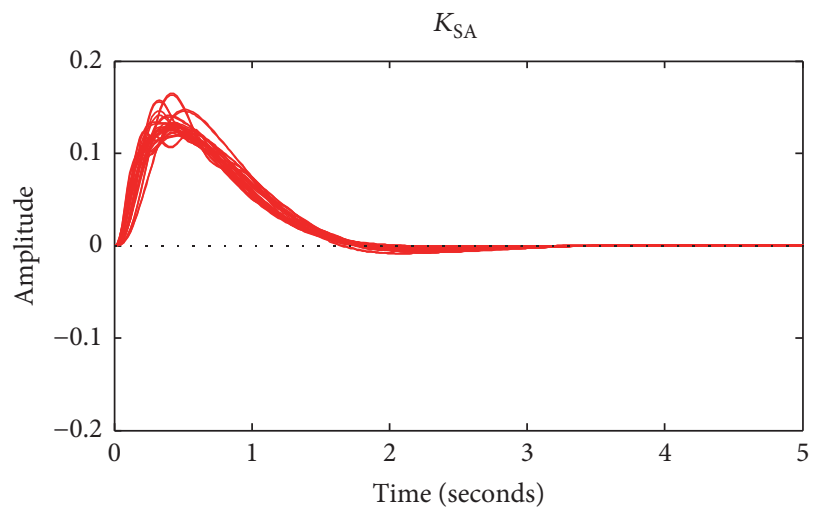

(c)

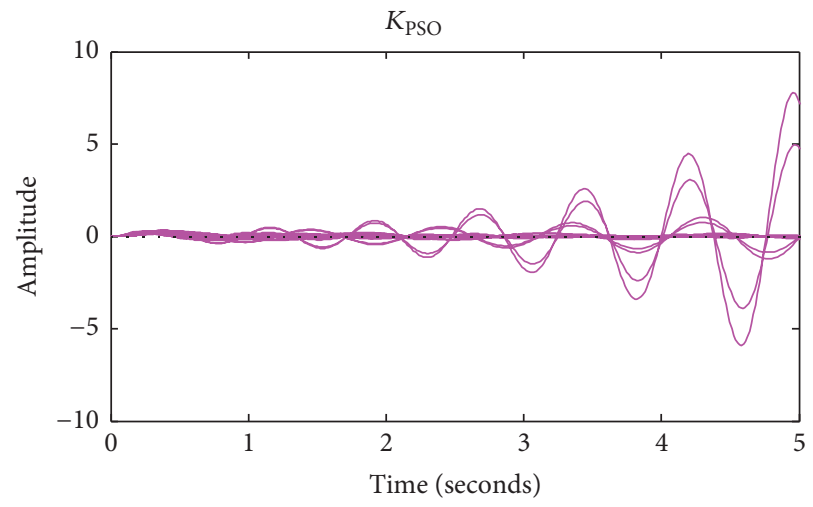

(e)

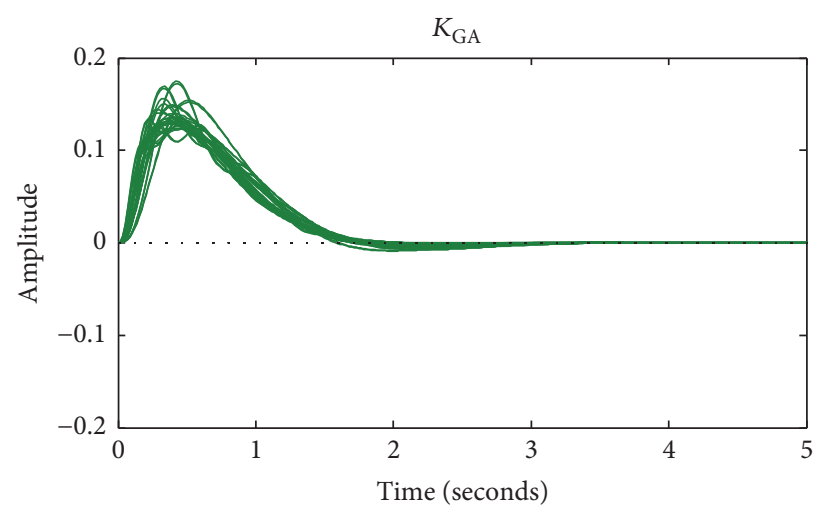

(b)

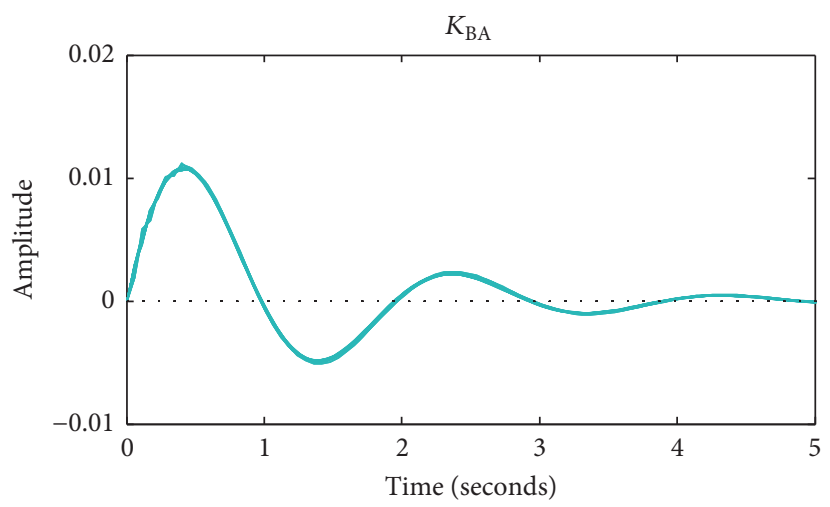

(d)

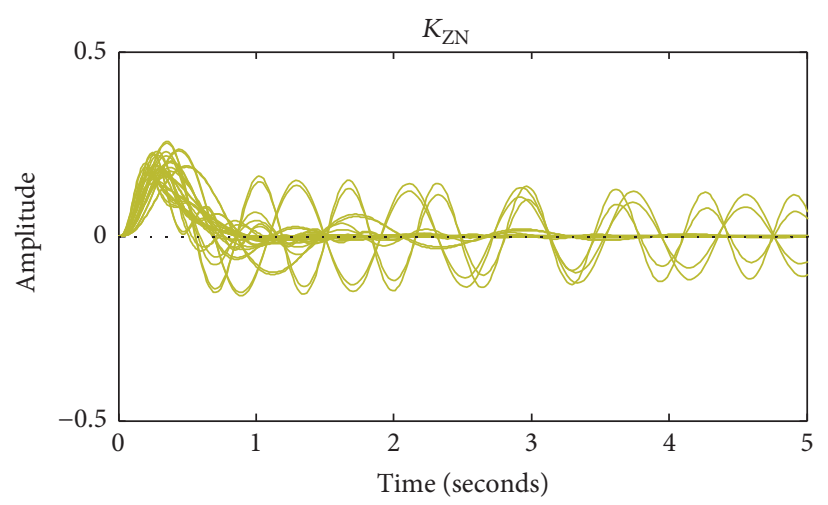

(f)

FIGURE 14: Compared plot for input disturbance rejection by the uncertain PMSM $( \pm 40 \%$ uncertainty range) with TLBO, GA, SA, BA, and PSO tuned QFT controller and Ziegler Nichols tuned PID controller.

controller gains to shape $L_{0}(j \omega)$ such that all the predefined objectives of robust stability and disturbance rejection are satisfied at all design frequencies. This naturally follows the QFT design process and also gives the designer a full control over the order and structure of the controller. The obtained results have been compared with classical PID tuning method of Ziegler-Nichols and QFT controller designed using other optimization algorithms. From the simulations and results, as obtained, it can be deducted that the TLBO designed QFT controller offers a better response than the ZN-PID controller and other tuning algorithms. The designed QFT controller efficiently handles the parametric uncertainties and results have been verified by taking an uncertain model of the PMSM with $\pm 10 \%$ and $\pm 40 \%$ uncertainty. The designed controller efficiently handles the parametric uncertainties and offers the response in a very tight envelope. So, there will be almost no effect on the PMSM's output in the presence of disturbances. Exploring the automatic synthesis of QFT for a nonlinear model of PMSM and the use of multiobjective algorithms for controller design can be taken in future work. 


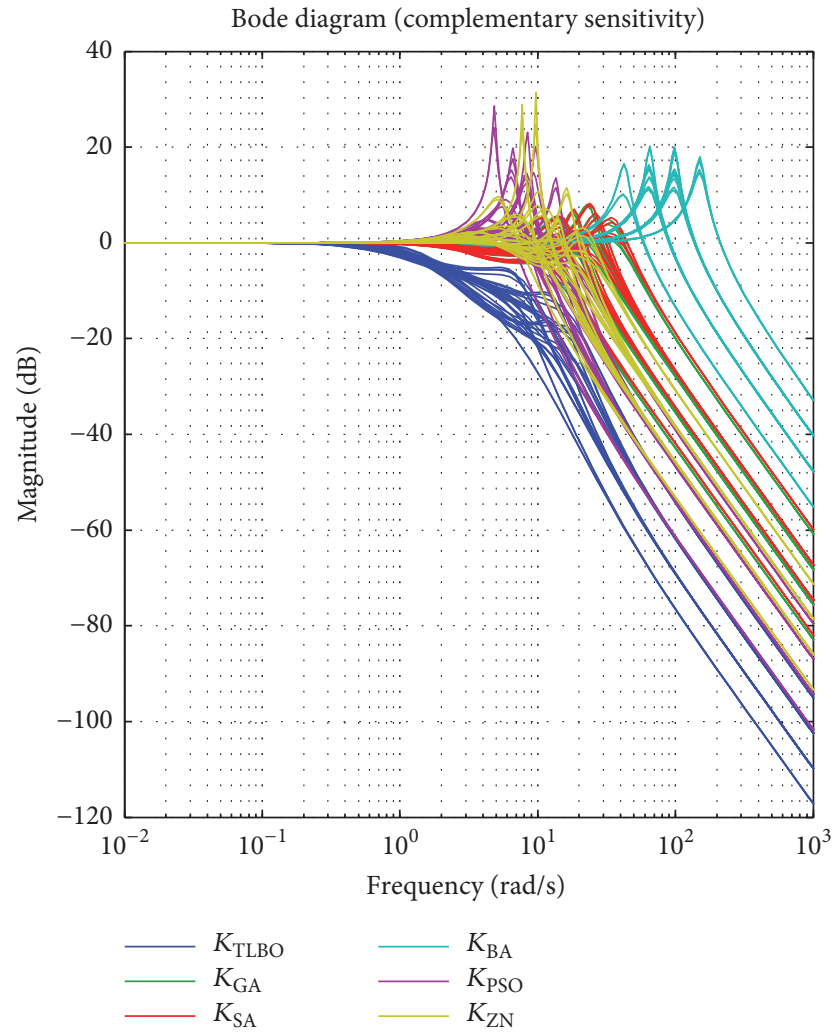

(a)

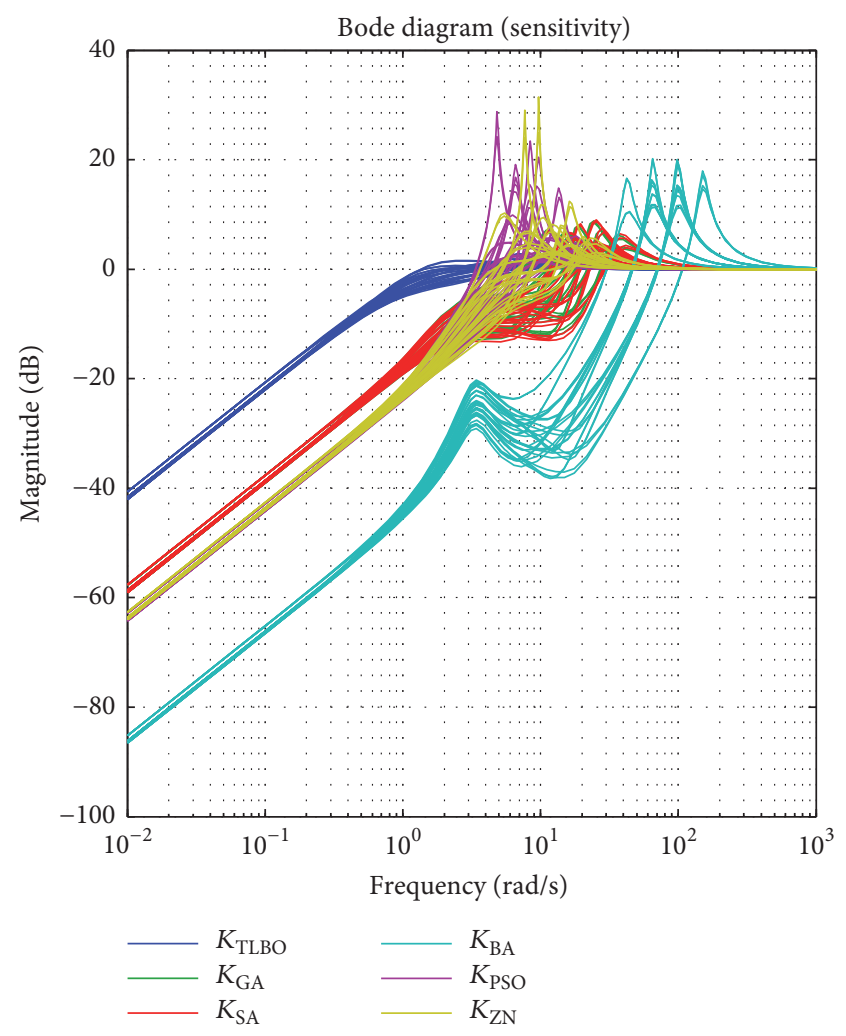

(b)

FIGURE 15: Compared frequency response of the uncertain PMSM ( $\pm 40 \%$ uncertainty range) with TLBO, GA, SA, BA, and PSO tuned QFT controller and Ziegler Nichols tuned PID controller.

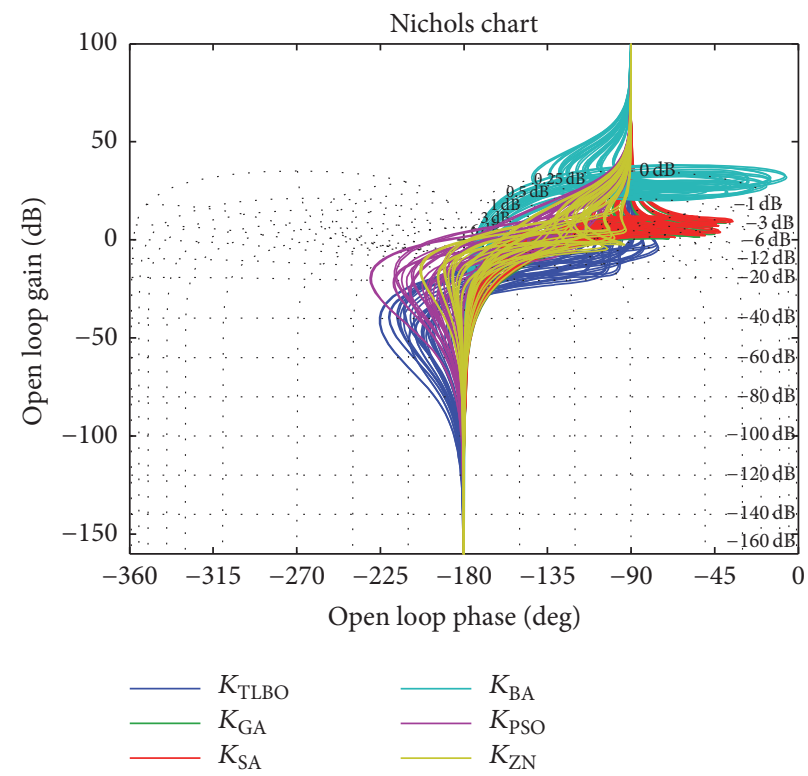

FIGURE 16: Compared Nichols chart for the open loop transmission $L_{0}(j \omega)$ of the uncertain PMSM ( $\pm 40 \%$ uncertainty range) with TLBO, GA, SA, BA, and PSO tuned QFT controller and Ziegler Nichols tuned PID controller. 


\section{Competing Interests}

The authors declare that there is no conflict of interests regarding the publication of this paper.

\section{References}

[1] I. M. Horowitz, Quantitative Feedback Design Theory (QFT), QFT, Boulder, Colo, USA, 1993.

[2] S. P. Bhattacharyya, H. Chapellat, and L. H. Keel, Robust Control: The Parametric Approach, Prentice Hall, 1st edition, 1995.

[3] C. Li, Z. Ye, Y. Wang, and L. Liu, "Design of attitude decoupling control system for BTT missile using quantitative feedback theory," in Proceedings of the International Conference on Modelling, Identification and Control (ICMIC '10), pp. 819-824, IEEE, July 2010.

[4] Z. Shi, F. Wang, and X.-Z. Wang, "Design of missile lateral channel controller based on QFT," in Proceedings of the International Conference on Computational and Information Sciences (ICCIS '11), pp. 917-920, IEEE, Chengdu, China, October 2011.

[5] A. R. Saxena and M. Veerachary, "QFT based robust controller design for fourth-order boost DC-DC switching power converter," in Proceedings of the Joint International Conference on Power Electronics, Drives and Energy Systems (PEDES '10), pp. 1-6, IEEE, New Delhi, India, December 2010.

[6] A. Khodabakhshian and R. Hemmati, "Robust decentralized multi-machine power system stabilizer design using quantitative feedback theory," International Journal of Electrical Power and Energy Systems, vol. 41, no. 1, pp. 112-119, 2012.

[7] S. M. M. Alavi and M. Saif, "A QFT-based decentralized design approach for integrated fault detection and control," IEEE Transactions on Control Systems Technology, vol. 20, no. 5, pp. 1366-1375, 2012.

[8] M. Barbu and S. Caraman, QFT Robust Control of Wastewater Treatment Processes, InTech, Rijeka, Croatia, 2011.

[9] D. Xu, K. He, Y. Wei, and J. Zhao, "Research on QFT controller design for LOS stabilization system of opto-electronic load for UAV," in Proceedings of the 10th World Congress on Intelligent Control and Automation (WCICA '12), pp. 1982-1986, Beijing, China, July 2012.

[10] K. Lu, Z. Wang, and Q. Cheng, "Design of flight control system for tiltrotor conversion using QFT," in Proceedings of the Chinese Control and Decision Conference (CCDC '14), pp. 3073-3076, Changsha, China, June 2014.

[11] F. Amini and J. Katebi, "Application of a robust QFT linear control in civil engineering," in Proceedings of the 14th World Conference on Earthquake Engineering, Beijing, China, 2008.

[12] A. Gera and I. Horowitz, "Optimization of the loop transfer function," International Journal of Control, vol. 31, no. 2, pp. 389398, 1980.

[13] D. J. Ballance and P. J. Gawthrop, "Control systems design via a quantitative feedback theory approach," in Proceedings of the International Conference on Control (Control '91), pp. 476-480, Edinburgh, UK, March 1991.

[14] R. Nandakumar, G. D. Halikias, and A. Zolotas, "Robust control design of a hydraulic actuator using the QFT method," in Proceedings of the 2007 9th European Control Conference (ECC '07), pp. 2908-2915, Kos, Greece, July 2007.

[15] R. Comasólivas, T. Escobet, and J. Quevedo, "Automatic loop shaping of QFT applied to an active control design,” in Proceedings of the 19th Mediterranean Conference on Control and
Automation (MED '11), pp. 718-723, IEEE, Corfu, Greece, June 2011.

[16] A. C. Zolotas and G. D. Halikias, "Optimal design of PID controllers using the QFT method," IEE Proceedings-Control Theory and Applications, vol. 146, no. 6, pp. 585-589, 1999.

[17] O. Yaniv, "Automatic loop shaping of MIMO controllers satisfying sensitivity specifications," Journal of Dynamic Systems, Measurement, and Control, vol. 128, no. 2, pp. 463-471, 2006.

[18] M. D. Patil and P. S. V. Nataraj, "Automated synthesis of multivariable QFT controller using interval constraint satisfaction technique," Journal of Process Control, vol. 22, no. 4, pp. 751-765, 2012.

[19] R. Kalla and P. S. V. Nataraj, "Synthesis of fractional-order QFT controllers using interval constraint satisfaction technique," in Proceedings of the 4th IFAC Workshop on Fractional Differentiation and Its Applications (FDA '10), Badajoz, Spain, 2010.

[20] M. D. Patil, P. S. Nataraj, and V. A. Vyawahare, "Automated design of fractional PI QFT controller using interval constraint satisfaction technique (ICST)," Nonlinear Dynamics, vol. 69, no. 3, pp. 1405-1422, 2012.

[21] R. Jeyasenthil and P. S. V. Nataraj, "utomatic loop shaping in QFT using hybrid optimization and consistency technique," Dynamics and Control of Process Systems, vol. 10, no. 1, pp. 427432, 2013.

[22] M. D. Patil and P. S. V. Nataraj, "Design of robust QFT controllers and prefilters for $3 \times 3$ distillation column," in Proceedings of the 10th Annual Conference of the IEEE India Council (INDICON '13), pp. 1-6, Mumbai, India, December 2013.

[23] P. S. V. Nataraj and M. D. Patil, "Robust control design for nonlinear magnetic levitation system using quantitative feedback theory (QFT)," in Proceedings of the Annual IEEE India Conference (INDICON'08), vol. 2, pp. 365-370, December 2008.

[24] A. Goldsztejn, F. Goualard, L. Granvilliers et al., "Robust controller and pre-filter design using QFT and interval constraint techniques," in Proceedings of the 7th International Workshop on Constraint Programming and Decision Making, 2014, http://coprod.constraintsolving.com/library/talk1.pdf.

[25] M. Garcia-Sanz and J. C. Guillen, "Automatic loop shaping of QFT robust controllers via genetic algorithms," in Proceedings of the 3rd IFAC Symposium on Robust Control Design, Praha, Czech Republic, 2000.

[26] W.-H. Chen, D. J. Ballance, W. Feng, and Y. Li, "Genetic algorithm enabled computer-automated design of QFT control systems," in Proceedings of the IEEE International Symposium on Computer Aided Control System Design, pp. 492-497, IEEE, Fairfax, Va, USA, August 1999.

[27] M.-S. Kim and C.-S. Chung, "Automatic loop-shaping of QFT controllers using GAs and evolutionary computation," in $A I$ 2005: advances in artificial intelligence, vol. 3809 of Lecture Notes in Comput. Sci., pp. 1096-1100, Springer, Berlin, Germany, 2005.

[28] C. Molins and M. Garcia-Sanz, "Automatic loop-shaping of QFT robust controllers," in Proceedings of the IEEE 2009 National Aerospace and Electronics Conference (NAECON '09), pp. 103110, Dayton, Ohio, USA, July 2009.

[29] B. Satpati, C. Koley, and S. Datta, "Robust PID controller design using particle swarm optimization-enabled automated quantitative feedback theory approach for a first-order lag system with minimal dead time," Systems Science and Control Engineering, vol. 2, no. 1, pp. 502-511, 2014.

[30] L. Meng and D. Xue, "Automatic loop shaping in fractionalorder QFT controllers using particle swarm optimizations," in 
Proceedings of the IEEE International Conference on Control and Automation, (ICCA '09), pp. 2182-2187, December 2009.

[31] L. Meng and D. Xue, "Design of a new fractional-order QFT controller based on automatic loop shaping," in Proceedings of the 8th World Congress on Intelligent Control and Automation (WCICA '10), pp. 3722-3727, Jinan, China, July 2010.

[32] L. Meng and D. Xue, "QFT fractional order robust controller for non-minimum phase hydro power plant," in Proceedings of the IEEE International Conference on Computer Science and Automation Engineering (CSAE '12), pp. 94-98, IEEE, Zhangjiajie, China, May 2012.

[33] R. V. Rao, V. J. Savsani, and D. P. Vakharia, "Teaching-learningbased optimization: a novel method for constrained mechanical design optimization problems," Computer Aided Design, vol. 43, no. 3, pp. 303-315, 2011.

[34] T. Niknam, R. Azizipanah-Abarghooee, and M. Rasoul Narimani, "A new multi objective optimization approach based on TLBO for location of automatic voltage regulators in distribution systems," Engineering Applications of Artificial Intelligence, vol. 25, no. 8, pp. 1577-1588, 2012.

[35] R. K. Sahu, T. S. Gorripotu, and S. Panda, "Automatic generation control of multi-area power systems with diverse energy sources using teaching learning based optimization algorithm," Engineering Science and Technology, vol. 19, no. 1, pp. 113-134, 2016.

[36] R. V. Rao and K. C. More, "Optimal design of the heat pipe using TLBO (teaching-learning-based optimization) algorithm," Energy, vol. 80, pp. 535-544, 2015.

[37] R. V. Rao and D. P. Rai, "Optimization of fused deposition modeling process using teaching-learning-based optimization algorithm," Engineering Science and Technology, an International Journal, vol. 19, no. 1, pp. 587-603, 2016.

[38] R. V. Rao and V. D. Kalyankar, Parameters Optimization of Advanced Machining Processes using TLBO Algorithm, vol. 20, EPPM, Singapore, 2011.

[39] Q. Niu, H. Zhang, and K. Li, "An improved TLBO with elite strategy for parameters identification of PEM fuel cell and solar cell models," International Journal of Hydrogen Energy, vol. 39, no. 8, pp. 3837-3854, 2014.

[40] B. K. Sahu, S. Pati, P. K. Mohanty, and S. Panda, "Teachinglearning based optimization algorithm based fuzzy-PID controller for automatic generation control of multi-area power system," Applied Soft Computing Journal, vol. 27, pp. 240-249, 2015.

[41] M. H. Khooban, "Design an intelligent proportional-derivative (PD) feedback linearization control for nonholonomic-wheeled mobile robot," Journal of Intelligent \& Fuzzy Systems, vol. 26, no. 4, pp. 1833-1843, 2014.

[42] T. Kenjo, Stepping Motors and their Microprocessor Controls, Clarendon Press, 1984.

[43] H. I. Ali, "Robust QFT controller design for positioning a permanent magnet stepper motors," International Journal of Computer and Electrical Engineering, vol. 1, no. 1, pp. 9-14, 2009.

[44] I. Horowitz, Synthesis of Feedback Systems, Academic Press, New York, NY, USA, 1963.

[45] K. Zhou and J. C. Doyle, Essentials of Robust Control, vol. 104, Prentice Hall, Upper Saddle River, NJ, USA, 1998.

[46] B. Azvine and R. Wynne, "A review of quantitative feedback theory as a robust control system design technique," Transactions of the Institute of Measurement and Control, vol. 14, no. 5, pp. 265-279, 1992. 


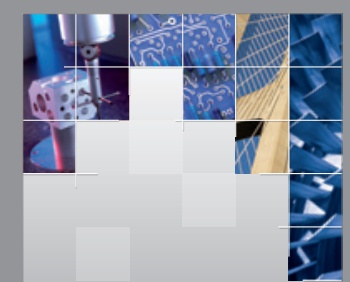

\section{Enfincering}
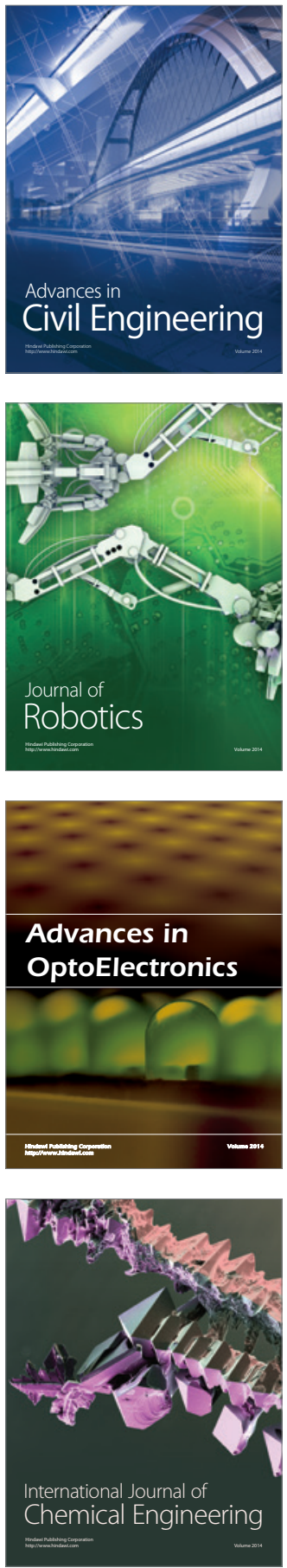

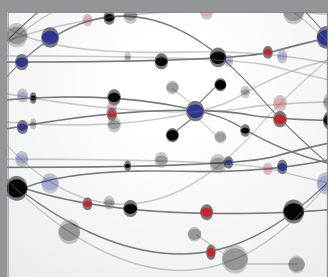

The Scientific World Journal

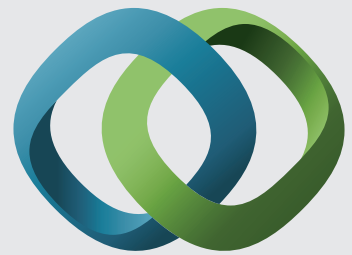

\section{Hindawi}

Submit your manuscripts at

http://www.hindawi.com
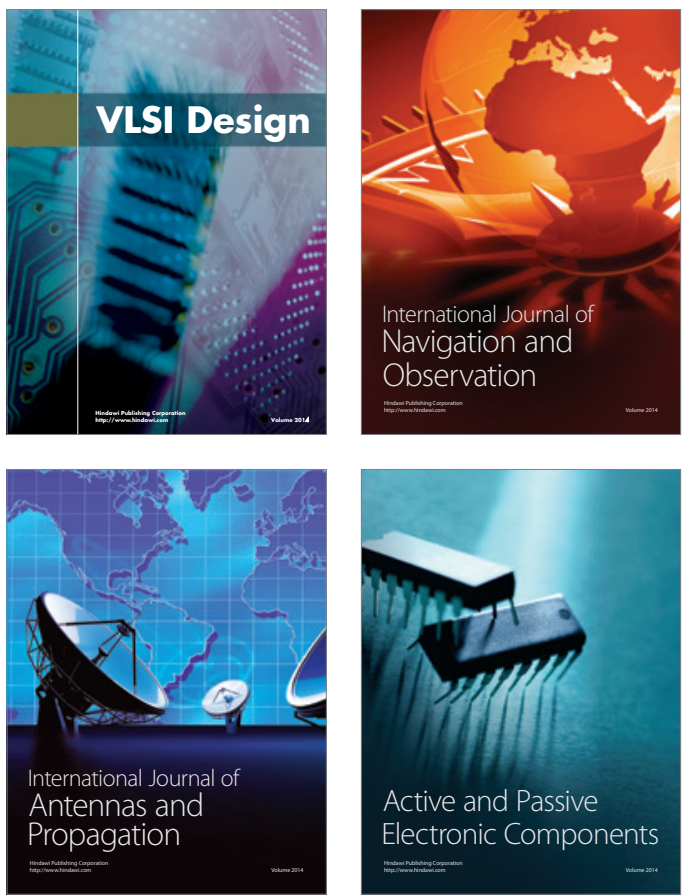
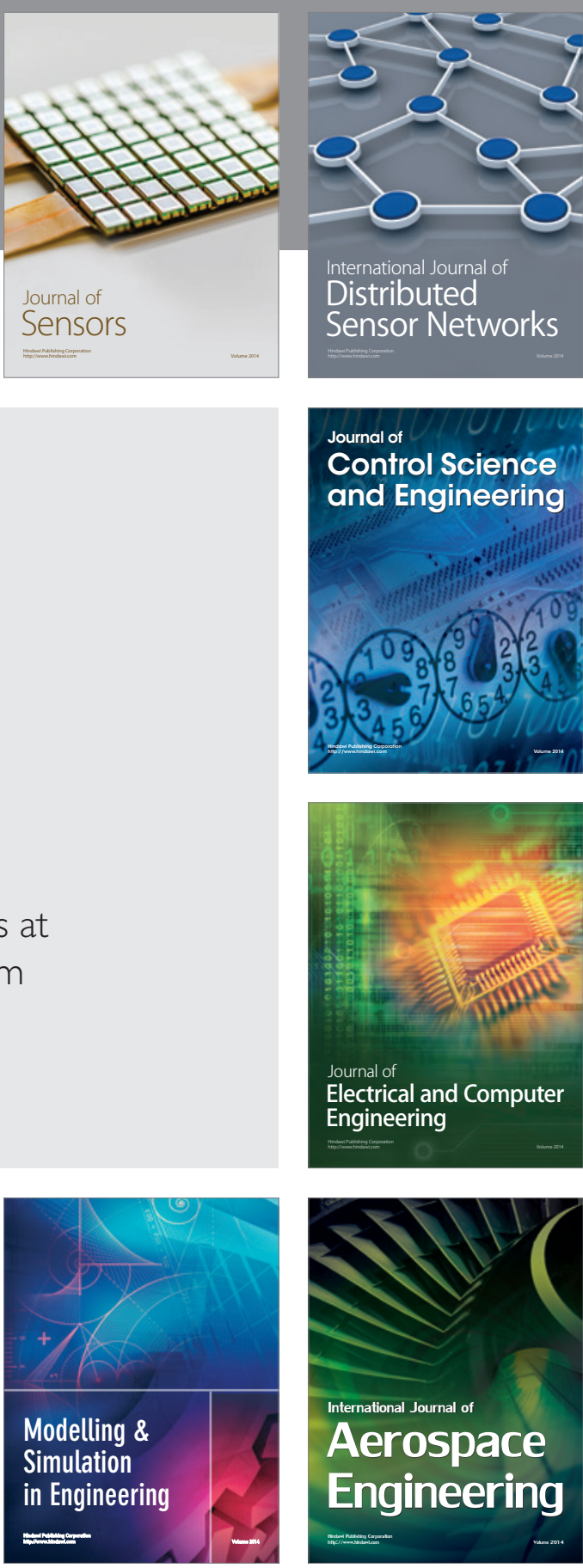

International Journal of

Distributed

Sensor Networks

Journal of

Control Science

and Engineering
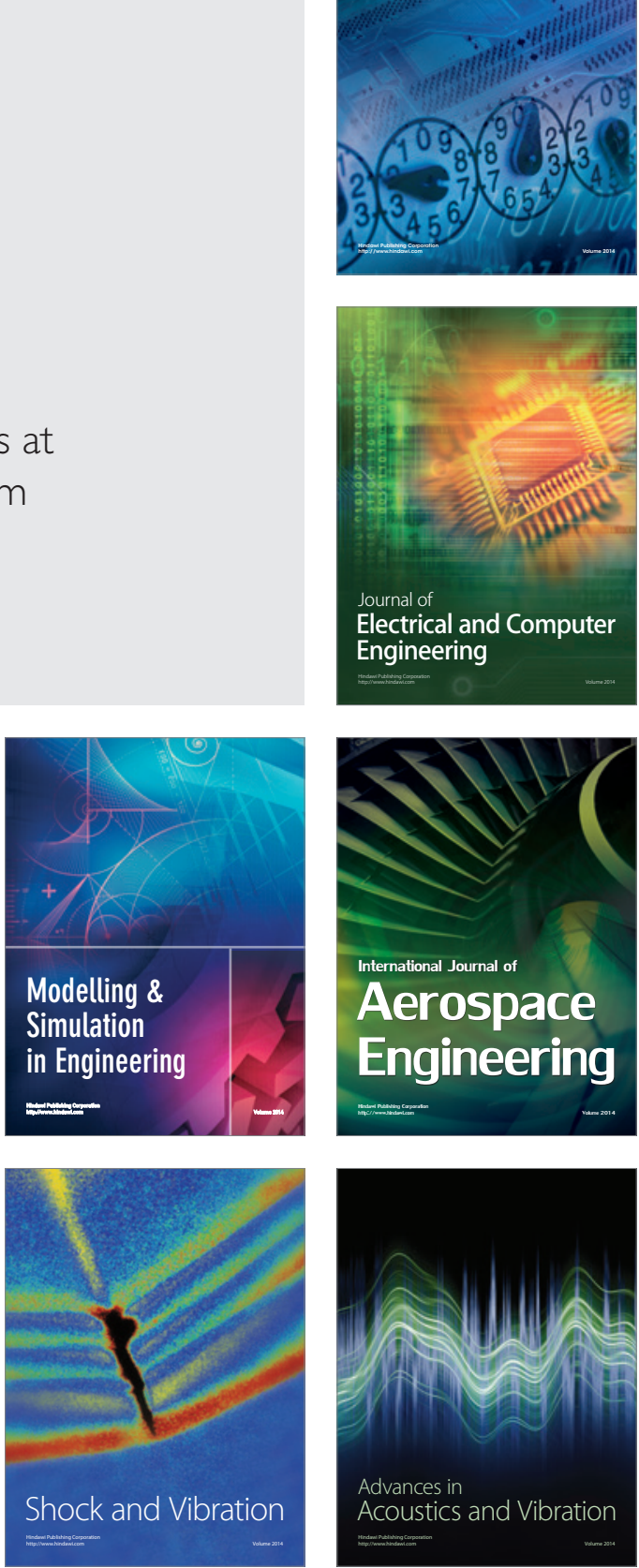